Supplement of Atmos. Meas. Tech., 11, 5587-5605, 2018

https://doi.org/10.5194/amt-11-5587-2018-supplement

(C) Author(s) 2018. This work is distributed under

the Creative Commons Attribution 4.0 License.

(c) (1)

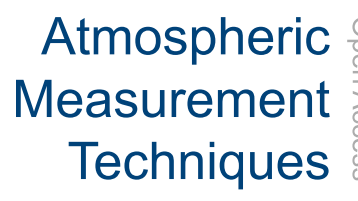

Supplement of

\title{
Retrievals of tropospheric ozone profiles from the synergism of AIRS and OMI: methodology and validation
}

\section{Dejian Fu et al.}

Correspondence to: Dejian Fu (dejian.fu@jpl.nasa.gov)

The copyright of individual parts of the supplement might differ from the CC BY 4.0 License. 


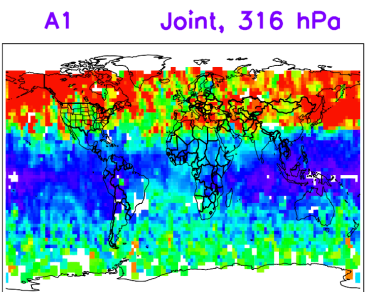

B 1
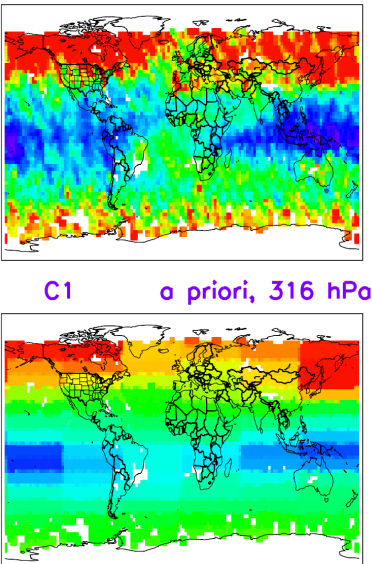

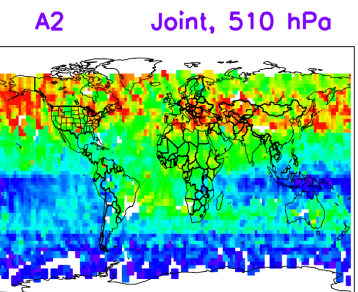

B2 TES, $510 \mathrm{hPo}$

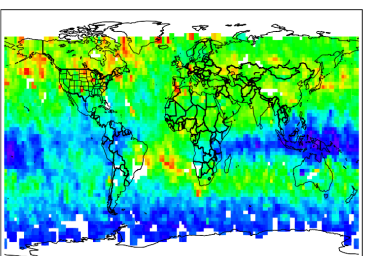

C2 o priori, $510 \mathrm{hPo}$

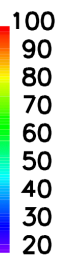

C2 a priori, $510 \mathrm{hPa}$

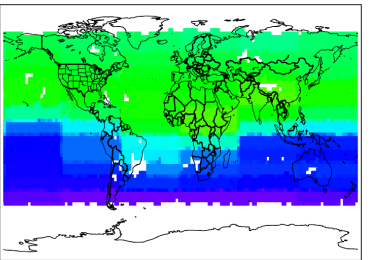

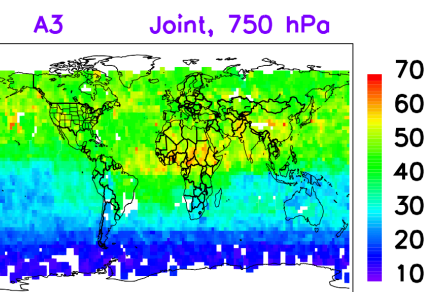

B3 TES, $750 \mathrm{hPo}$

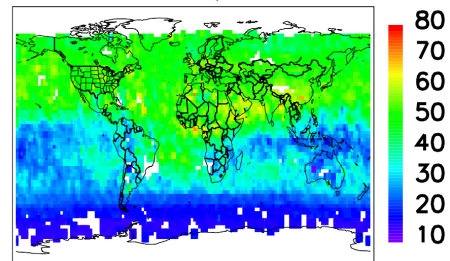

C3 a priori, $750 \mathrm{hPo}$

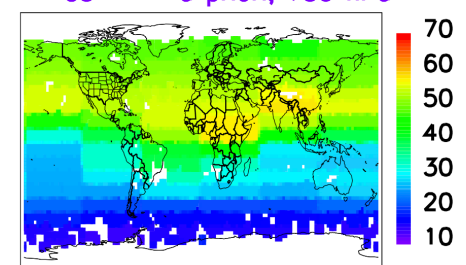

Figure S1: Global maps of monthly averaged ozone $\left(\mathrm{O}_{3}\right)$ volume mixing ratio (VMR) with a unit of ppb. The A-Train measurements in January 2006 were used in creating these global maps. Comparison of Joint AIRS+OMI (top row, A), TES (middle row, B), and a priori (bottom row C) ozone VMR for the pressure level of 316, 510 and $750 \mathrm{hPa}$ (columns left, middle, right), respectively. All data have been gridded to $2.5^{\circ} \times 2.5^{\circ}$ cells. 

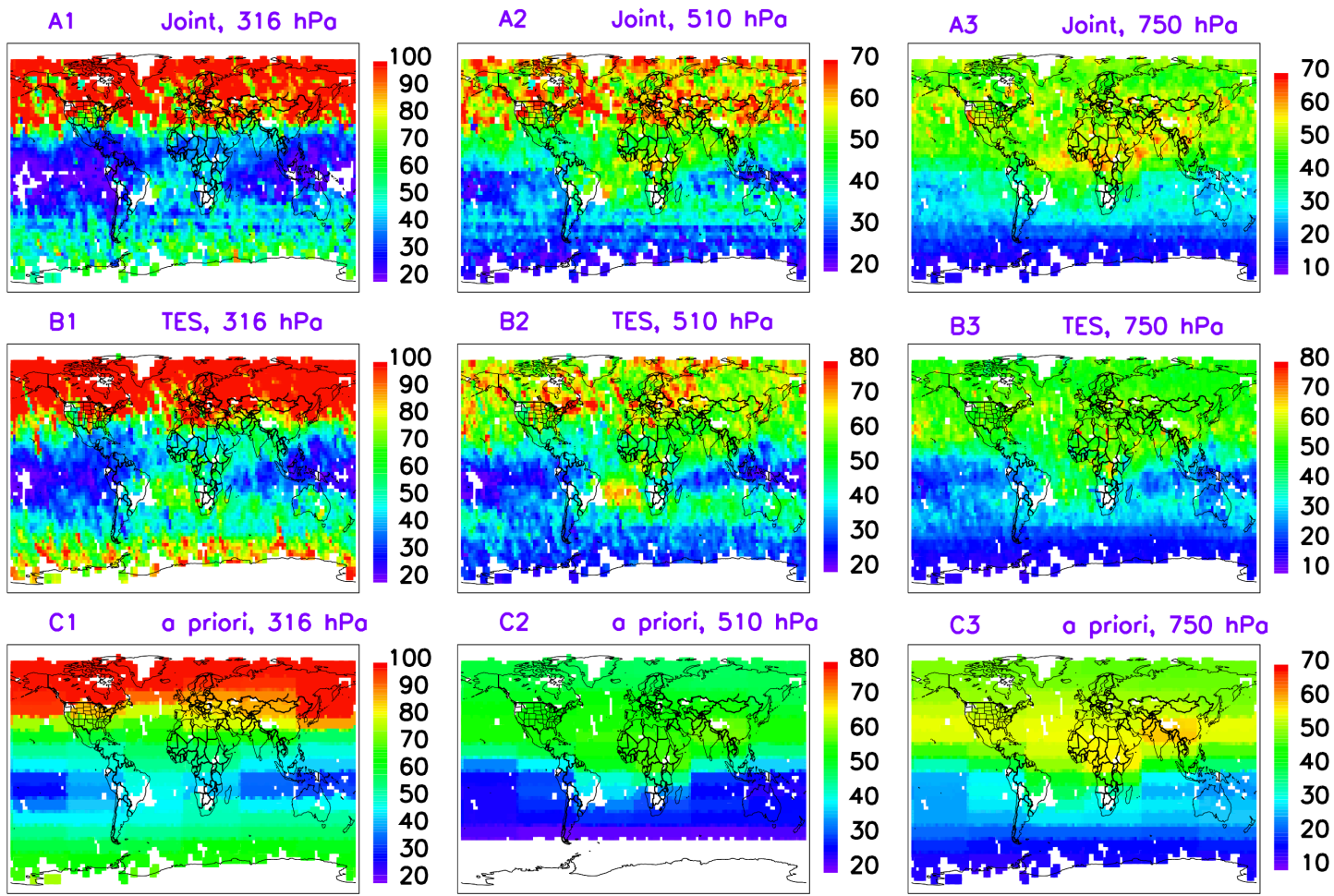

Figure S2: Global maps of monthly averaged ozone $\left(\mathrm{O}_{3}\right)$ volume mixing ratio (VMR) with a unit of ppb. The A-Train measurements in February 2006 were used in creating these global maps. Comparison of Joint AIRS+OMI (top row, A), TES (middle row, B), and a priori (bottom row C) ozone VMR for the pressure level of 316, 510 and 750 hPa (columns left, middle, right), respectively. All data have been gridded to $2.5^{\circ} \times 2.5^{\circ}$ cells. 

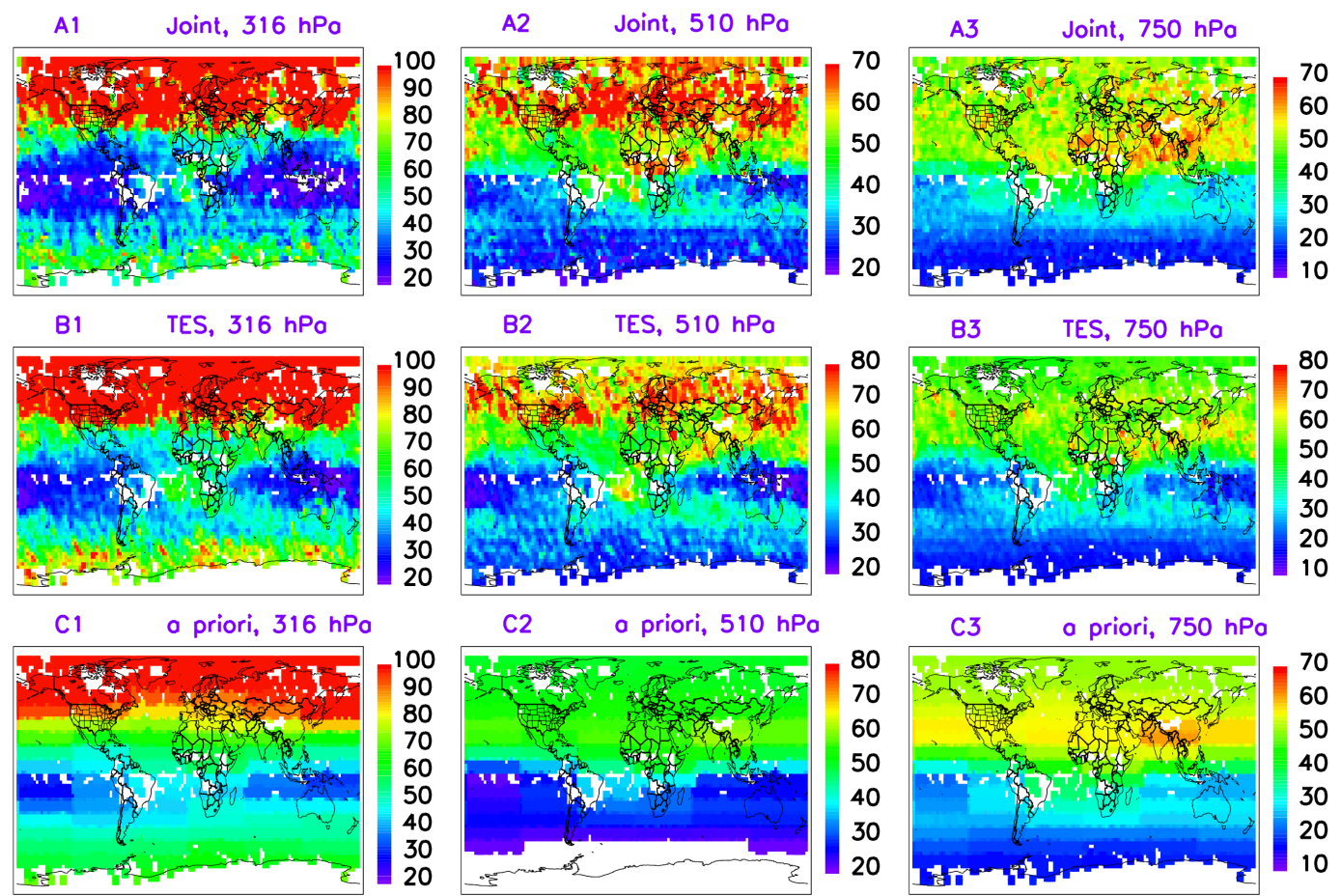

Figure S3: Global maps of monthly averaged ozone $\left(\mathrm{O}_{3}\right)$ volume mixing ratio (VMR) with a unit of ppb. The A-Train measurements in March 2006 were used in creating these global maps. Comparison of Joint AIRS+OMI (top row, A), TES (middle row, B), and a priori (bottom row C) ozone VMR for the pressure level of 316, 510 and $750 \mathrm{hPa}$ (columns left, middle, 5 right), respectively. All data have been gridded to $2.5^{\circ} \times 2.5^{\circ}$ cells. 

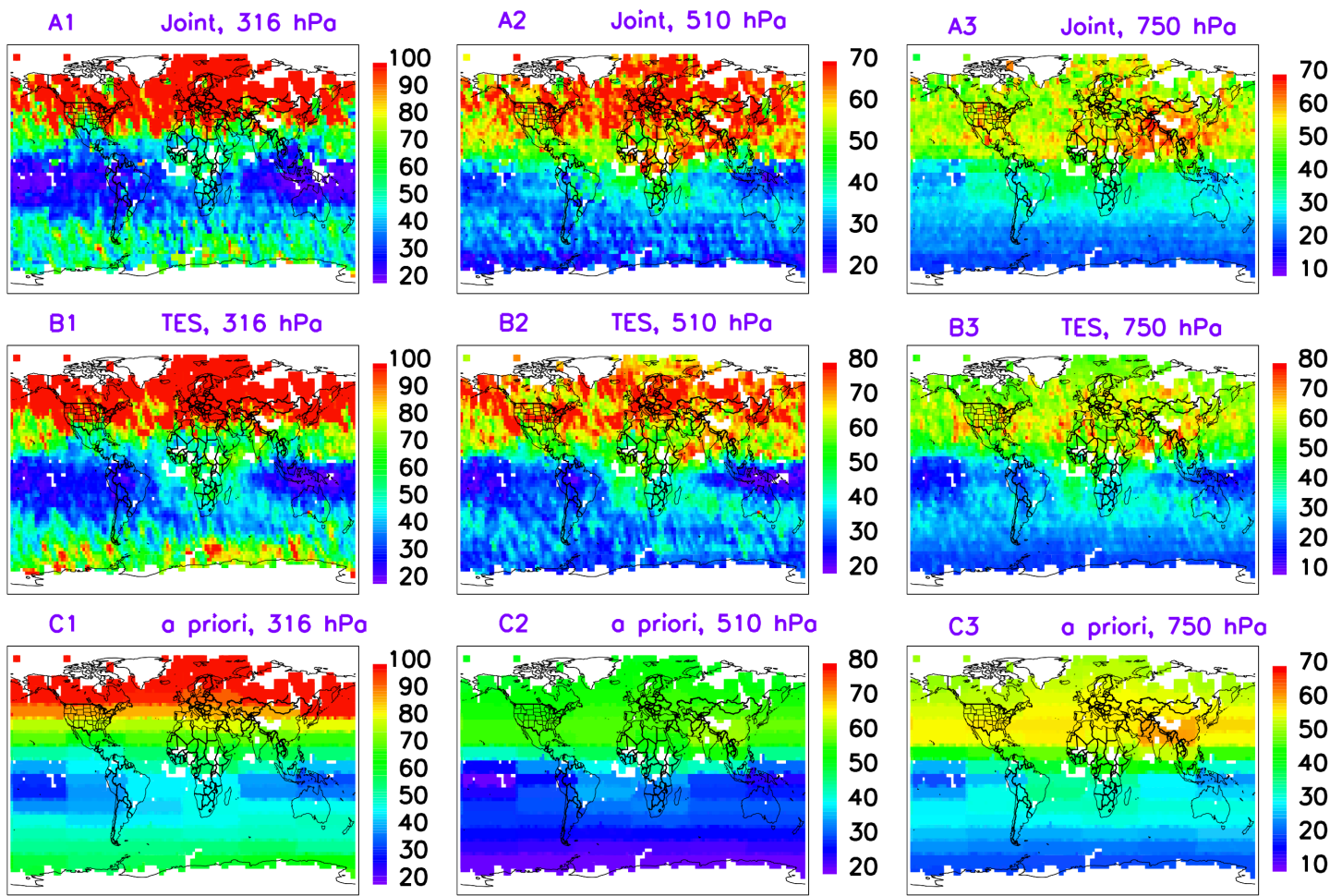

Figure S4: Global maps of monthly averaged ozone $\left(\mathrm{O}_{3}\right)$ volume mixing ratio (VMR) with a unit of ppb. The A-Train measurements in April 2006 were used in creating these global maps. Comparison of Joint AIRS+OMI (top row, A), TES (middle row, B), and a priori (bottom row C) ozone VMR for the pressure level of 316, 510 and 750 hPa (columns left, middle, right), respectively. All data have been gridded to $2.5^{\circ} \times 2.5^{\circ}$ cells. 

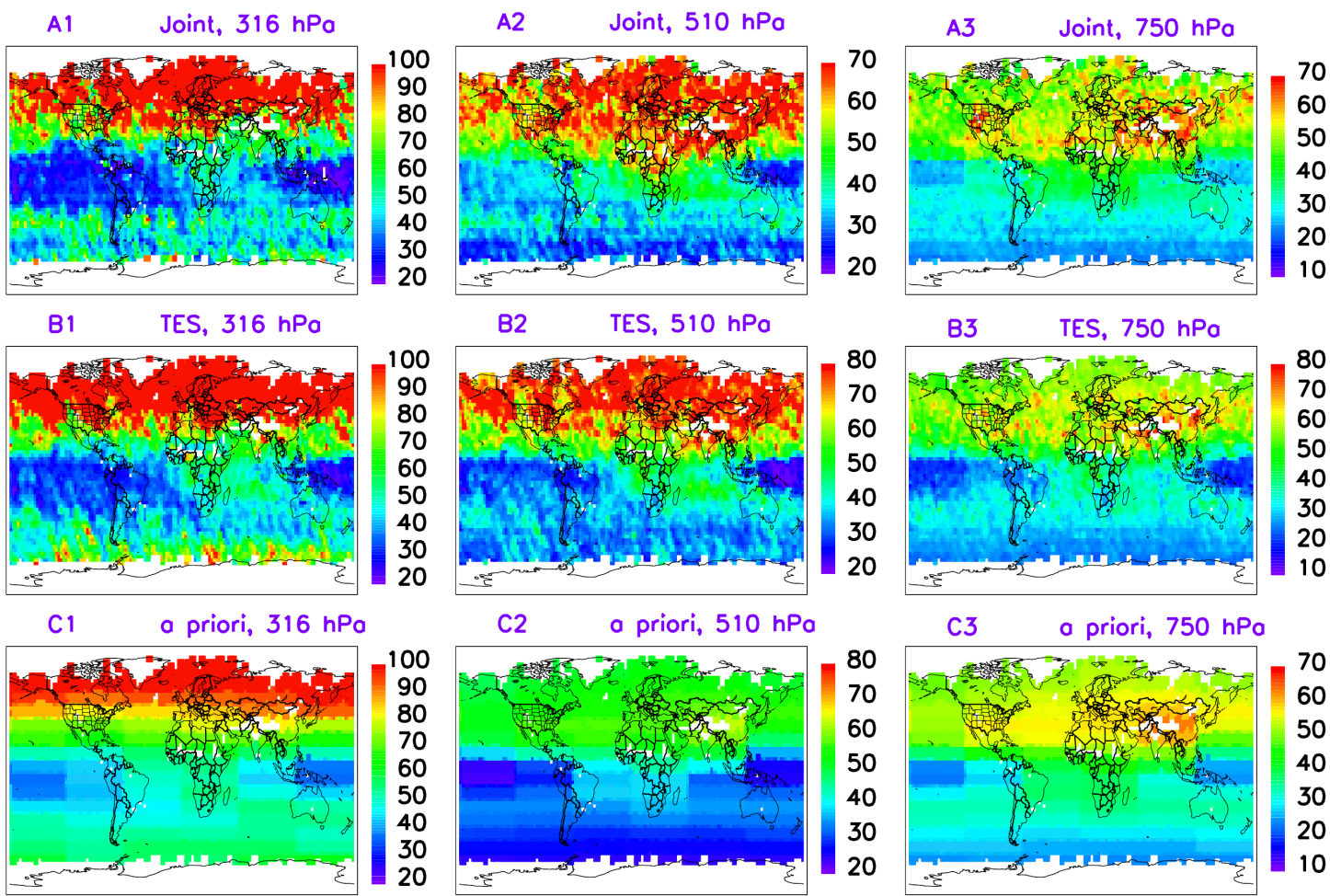

Figure S5: Global maps of monthly averaged ozone $\left(\mathrm{O}_{3}\right)$ volume mixing ratio (VMR) with a unit of ppb. The A-Train measurements in May 2006 were used in creating these global maps. Comparison of Joint AIRS+OMI (top row, A), TES (middle row, B), and a priori (bottom row C) ozone VMR for the pressure level of 316, 510 and $750 \mathrm{hPa}$ (columns left, middle, right), respectively. All data have been gridded to $2.5^{\circ} \times 2.5^{\circ}$ cells. 

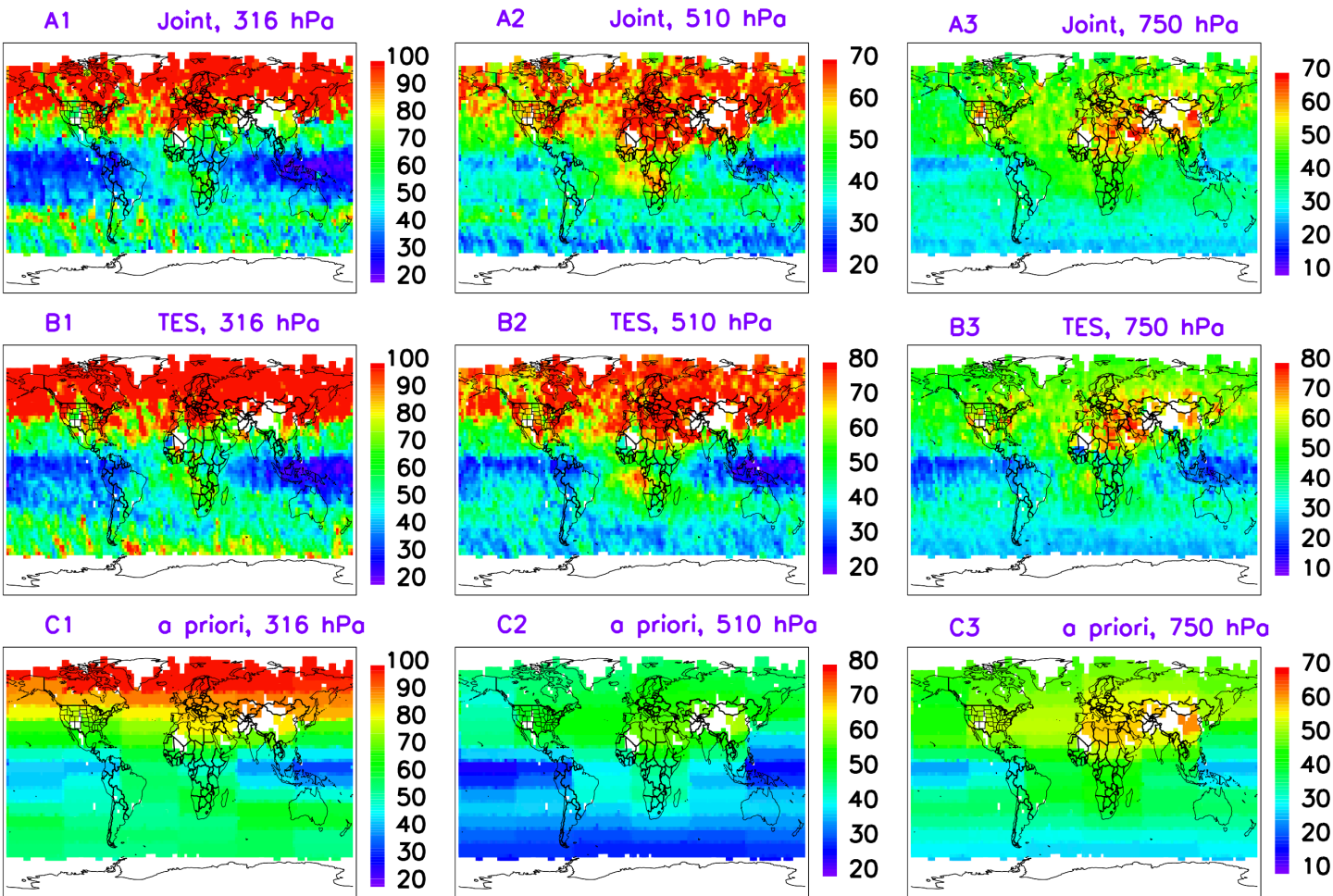

Figure S6: Global maps of monthly averaged ozone $\left(\mathrm{O}_{3}\right)$ volume mixing ratio (VMR) with a unit of ppb. The A-Train measurements in June 2006 were used in creating these global maps. Comparison of Joint AIRS+OMI (top row, A), TES (middle row, B), and a priori (bottom row C) ozone VMR for the pressure level of 316, 510 and 750 hPa (columns left, middle, right), respectively. All data have been gridded to $2.5^{\circ} \times 2.5^{\circ}$ cells. 

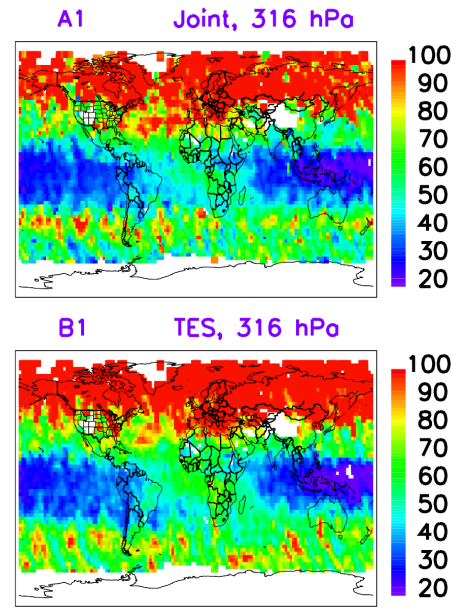

C1 a priori, $316 \mathrm{hPa}$
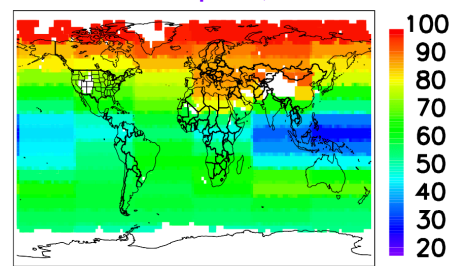
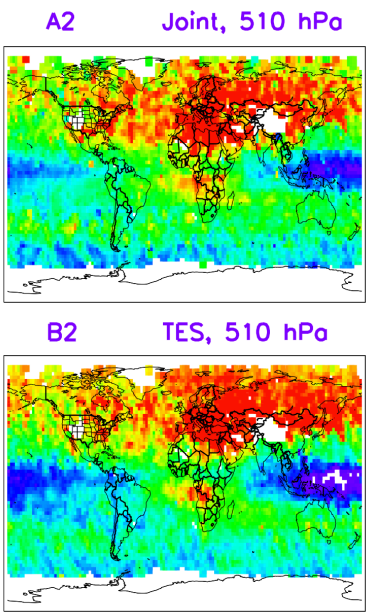

C2

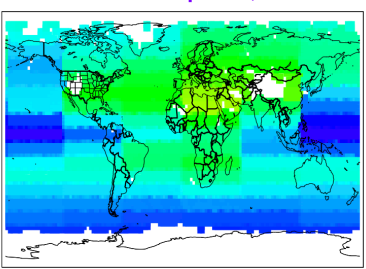

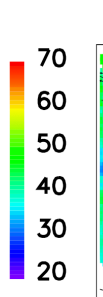
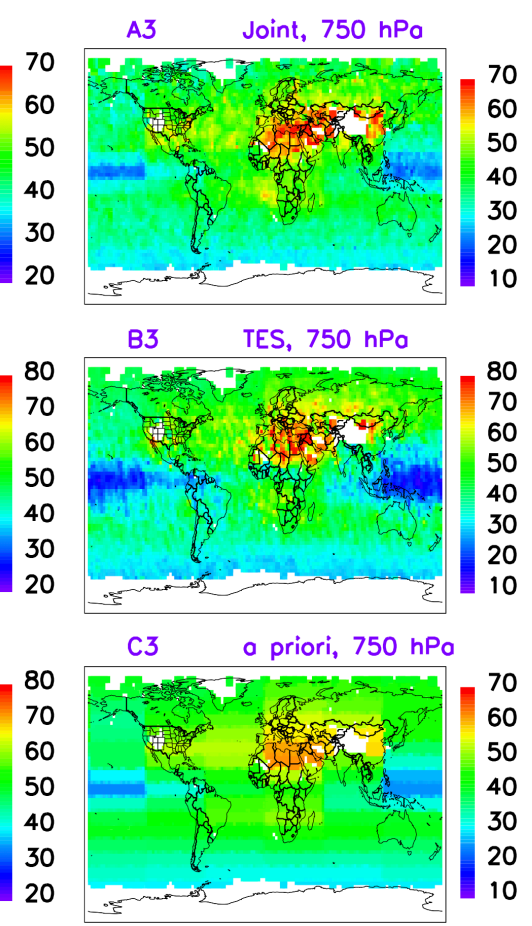

Figure S7: Global maps of monthly averaged ozone $\left(\mathrm{O}_{3}\right)$ volume mixing ratio (VMR) with a unit of ppb. The A-Train measurements in July 2006 were used in creating these global maps. Comparison of Joint AIRS+OMI (top row, A), TES (middle row, B), and a priori (bottom row C) ozone VMR for the pressure level of 316, 510 and $750 \mathrm{hPa}$ (columns left, middle, right), respectively. All data have been gridded to $2.5^{\circ} \times 2.5^{\circ}$ cells. 

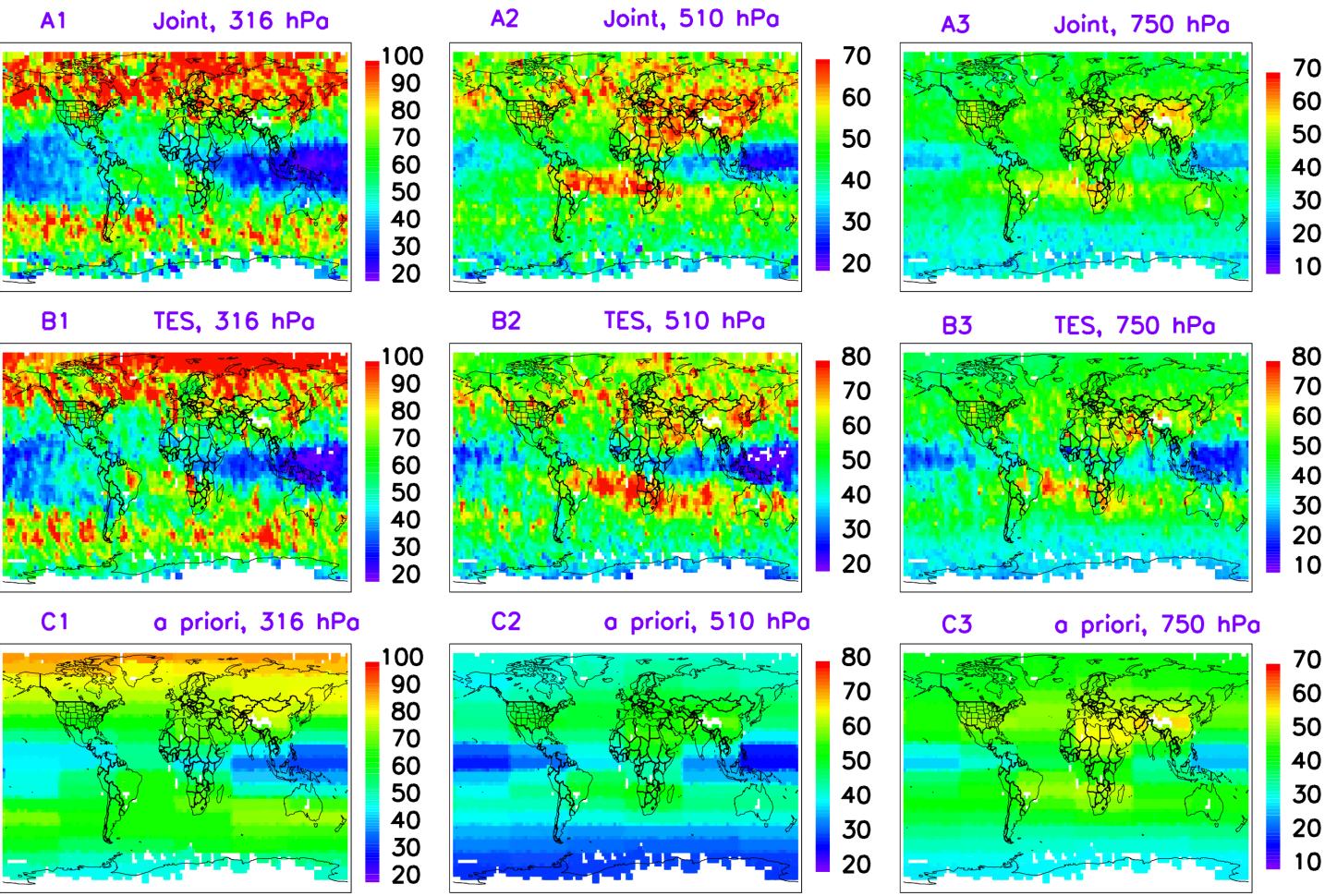

Figure S8: Global maps of monthly averaged ozone $\left(\mathrm{O}_{3}\right)$ volume mixing ratio (VMR) with a unit of ppb. The A-Train measurements in September 2006 were used in creating these global maps. Comparison of Joint AIRS+OMI (top row, A), TES (middle row, B), and a priori (bottom row C) ozone VMR for the pressure level of 316, 510 and $750 \mathrm{hPa}$ (columns left, middle, 5 right), respectively. All data have been gridded to $2.5^{\circ} \times 2.5^{\circ}$ cells. 

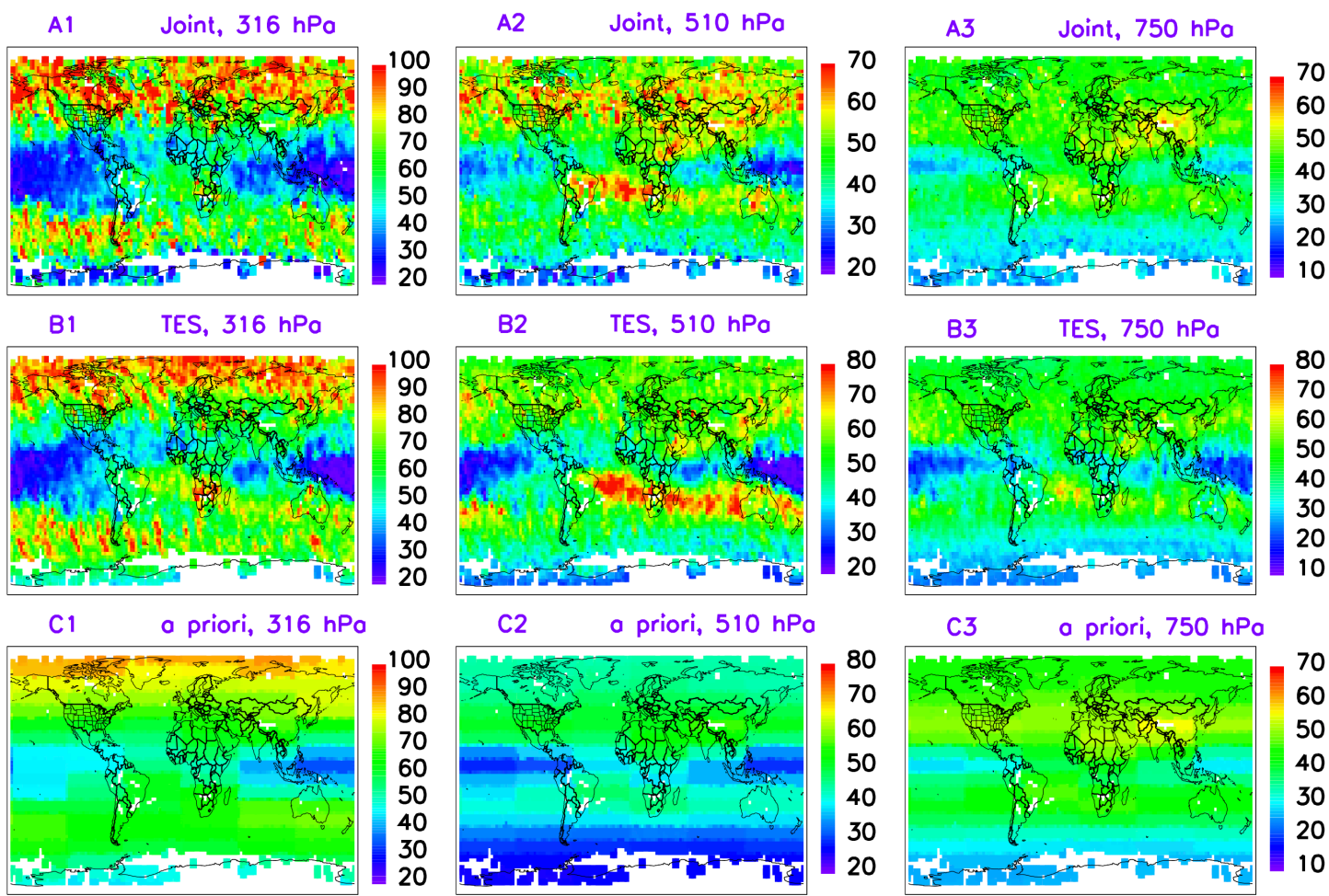

Figure S9: Global maps of monthly averaged ozone $\left(\mathrm{O}_{3}\right)$ volume mixing ratio (VMR) with a unit of ppb. The A-Train measurements in October 2006 were used in creating these global maps. Comparison of Joint AIRS+OMI (top row, A), TES (middle row, B), and a priori (bottom row C) ozone VMR for the pressure level of 316, 510 and $750 \mathrm{hPa}$ (columns left, middle, 5 right), respectively. All data have been gridded to $2.5^{\circ} \times 2.5^{\circ}$ cells. 


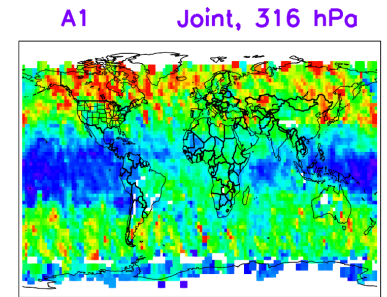

B1

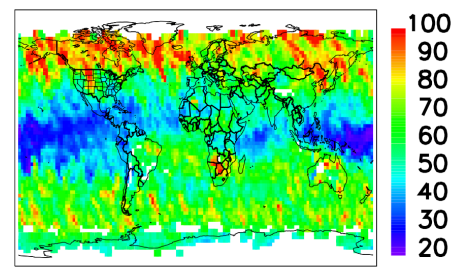

C1

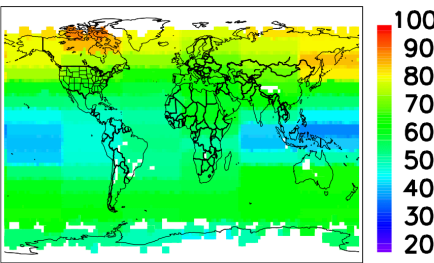

A2 Joint, $510 \mathrm{hPo}$

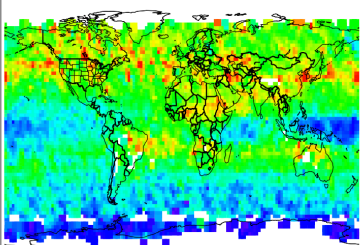

B2

TES, $510 \mathrm{hPo}$

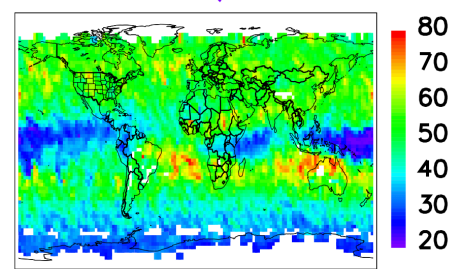

C2 a priori, $510 \mathrm{hPo}$

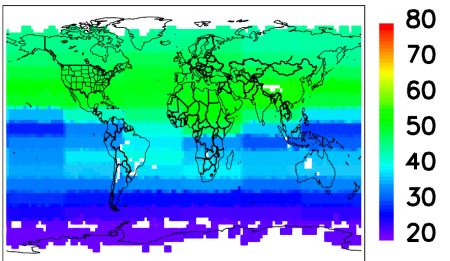

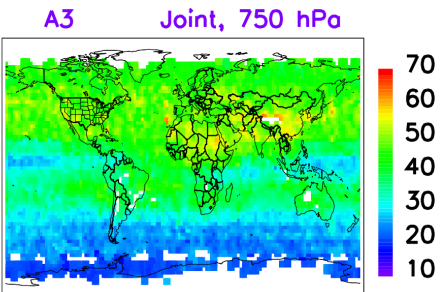

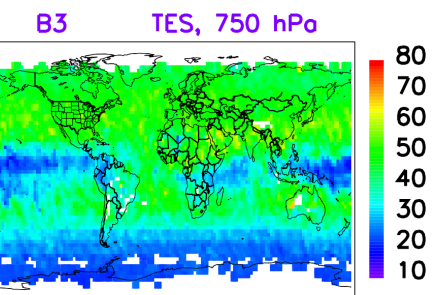

a priori, $750 \mathrm{hPo}$

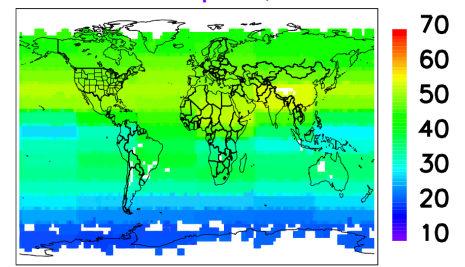

Figure S10: Global maps of monthly averaged ozone $\left(\mathrm{O}_{3}\right)$ volume mixing ratio (VMR) with a unit of ppb. The A-Train measurements in November 2006 were used in creating these global maps. Comparison of Joint AIRS+OMI (top row, A), TES (middle row, B), and a priori (bottom row C) ozone VMR for the pressure level of 316, 510 and $750 \mathrm{hPa}$ (columns left, middle, right), respectively. All data have been gridded to $2.5^{\circ} \times 2.5^{\circ}$ cells. 

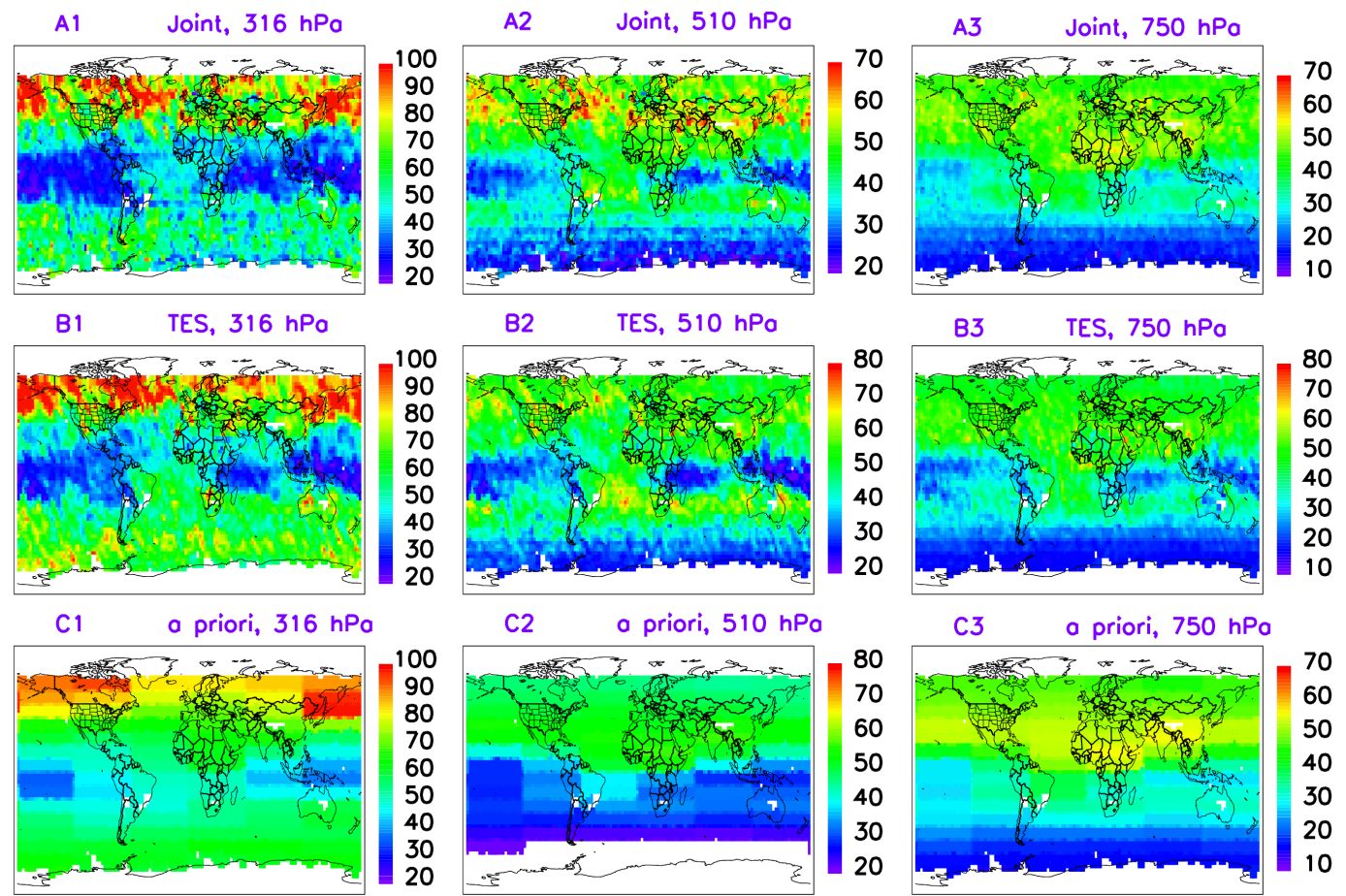

Figure S11: Global maps of monthly averaged ozone $\left(\mathrm{O}_{3}\right)$ volume mixing ratio (VMR) with a unit of ppb. The A-Train measurements in December 2006 were used in creating these global maps. Comparison of Joint AIRS+OMI (top row, A), TES (middle row, B), and a priori (bottom row C) ozone VMR for the pressure level of 316, 510 and $750 \mathrm{hPa}$ (columns left, middle, right), respectively. All data have been gridded to $2.5^{\circ} \times 2.5^{\circ}$ cells. 

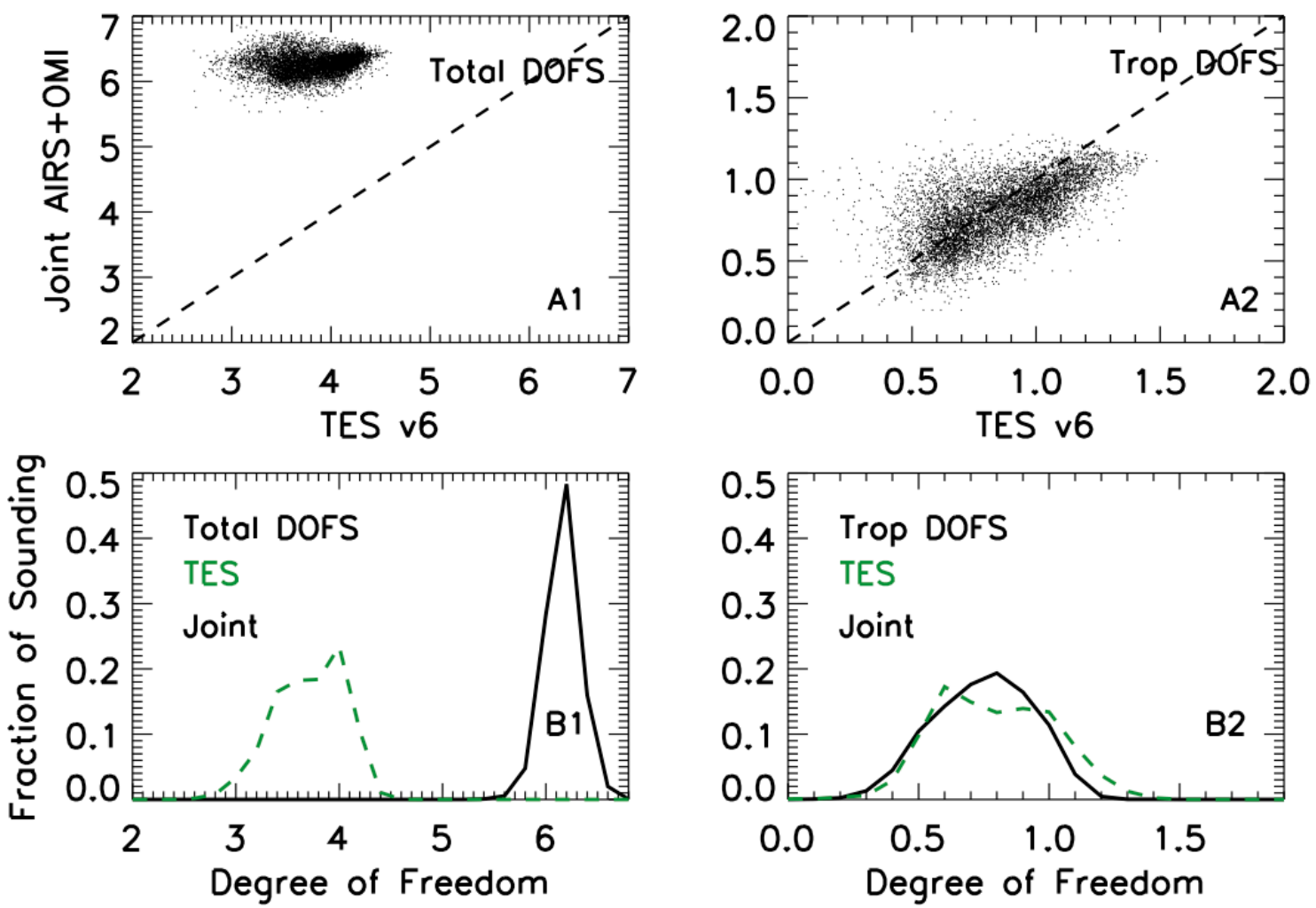

Figure S12: Degree of freedom of signals (DOFS) for January 2006 monthly mean $\mathrm{O}_{3}$ over globe shown in Fig. S1. (A1) total DOFS; (A2) tropospheric DOFS; and (B1) histogram of total DOFS: joint AIRS+OMI (black line) and TES version 6 (green dash); (B2) histogram of tropospheric DOFS joint AIRS+OMI (black line) and TES version 6 (green dash). 

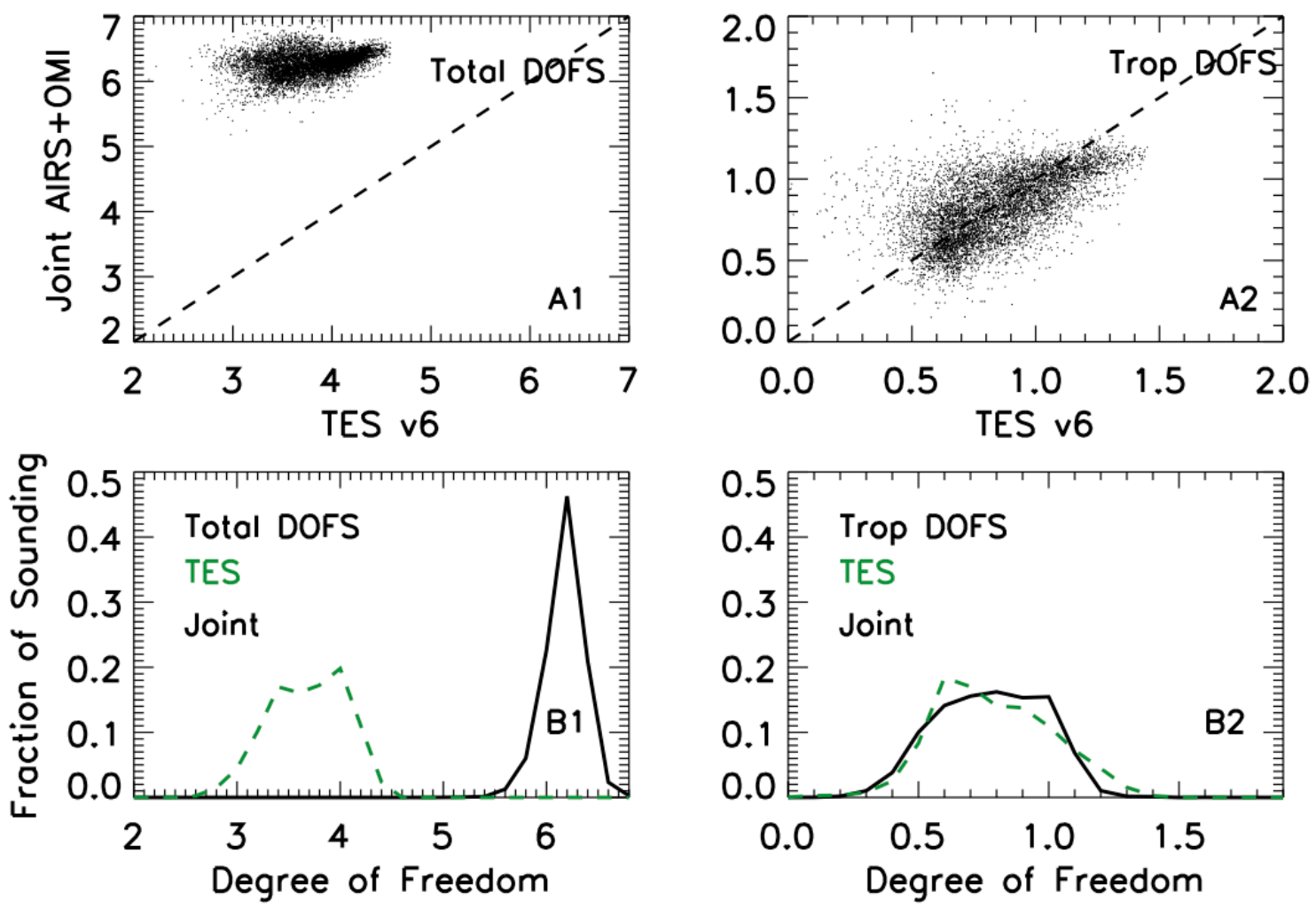

Figure S13: Degree of freedom of signals (DOFS) for February 2006 monthly mean O $_{3}$ over globe shown in Fig. S2. (A1) total DOFS; (A2) tropospheric DOFS; and (B1) histogram of total DOFS: joint AIRS+OMI (black line) and TES version 6 (green dash); (B2) histogram of tropospheric DOFS joint AIRS+OMI (black line) and TES version 6 (green dash). 

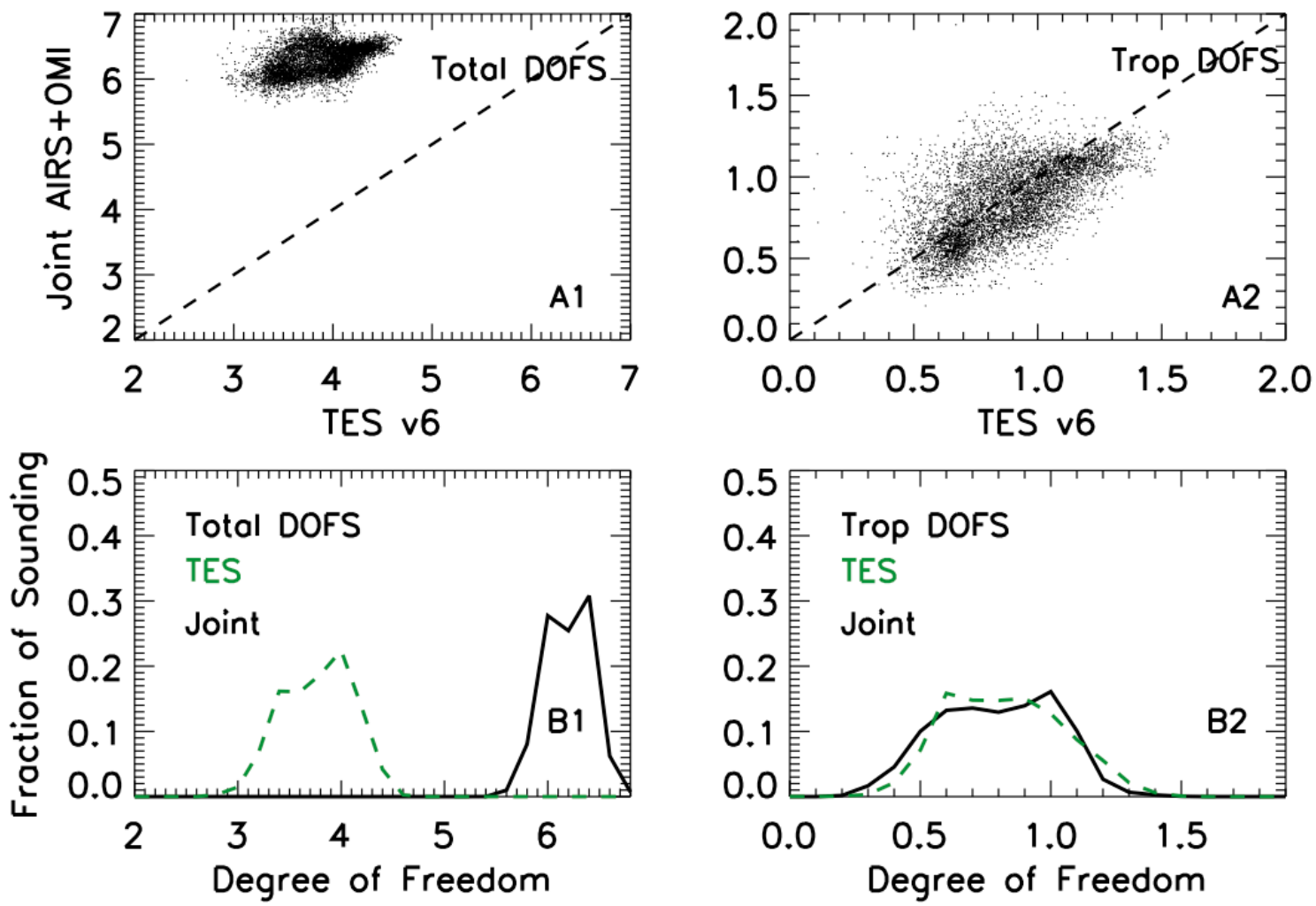

Figure S14: Degree of freedom of signals (DOFS) for March 2006 monthly mean $\mathrm{O}_{3}$ over globe shown in Fig. S3. (A1) total DOFS; (A2) tropospheric DOFS; and (B1) histogram of total DOFS: joint AIRS+OMI (black line) and TES version 6 (green dash); (B2) 5 histogram of tropospheric DOFS joint AIRS+OMI (black line) and TES version 6 (green dash). 

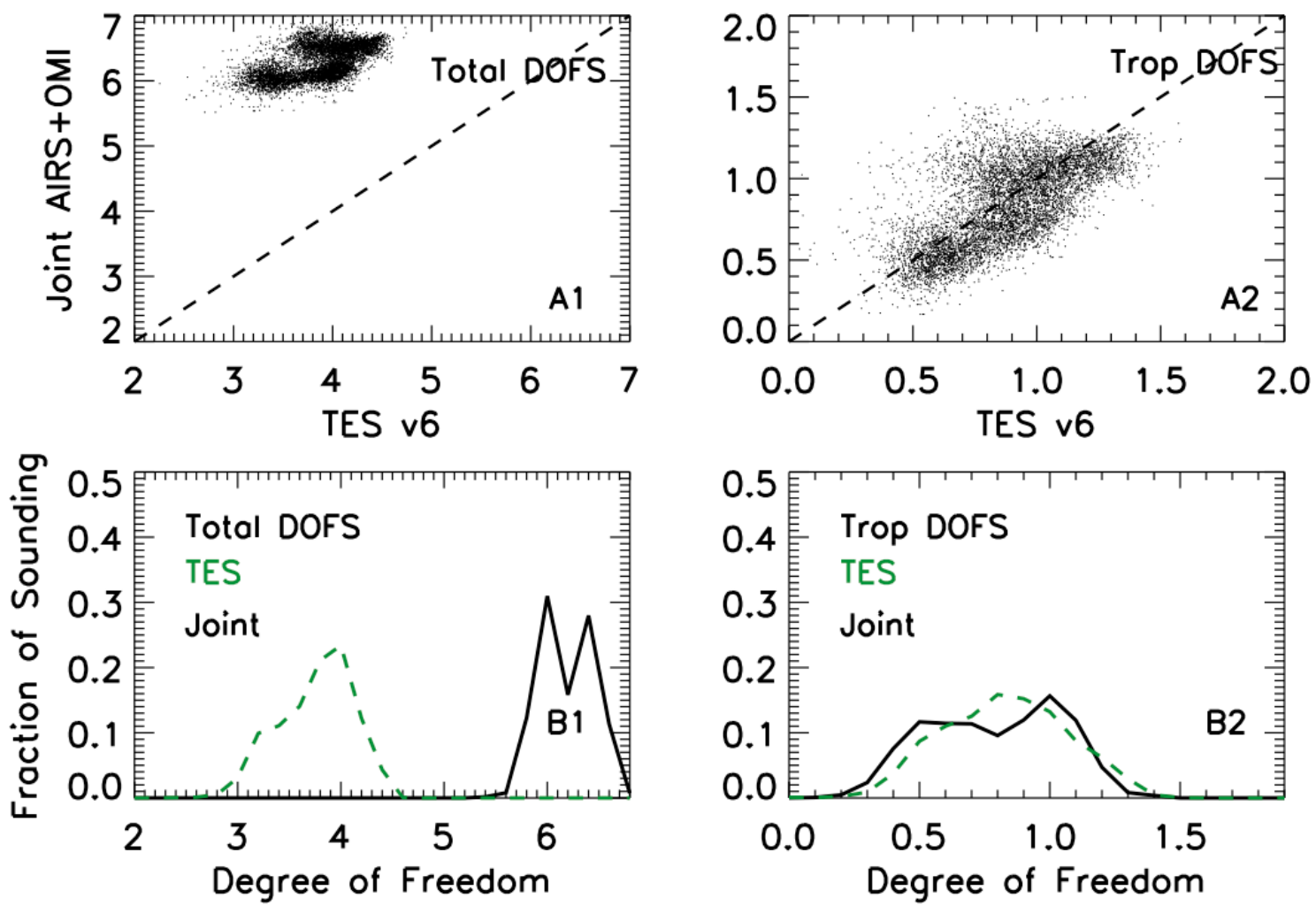

Figure S15: Degree of freedom of signals (DOFS) for April 2006 monthly mean O3 over globe shown in Fig. S4. (A1) total DOFS; (A2) tropospheric DOFS; and (B1) histogram of total DOFS: joint AIRS+OMI (black line) and TES version 6 (green dash); (B2) 5 histogram of tropospheric DOFS joint AIRS+OMI (black line) and TES version 6 (green dash). 

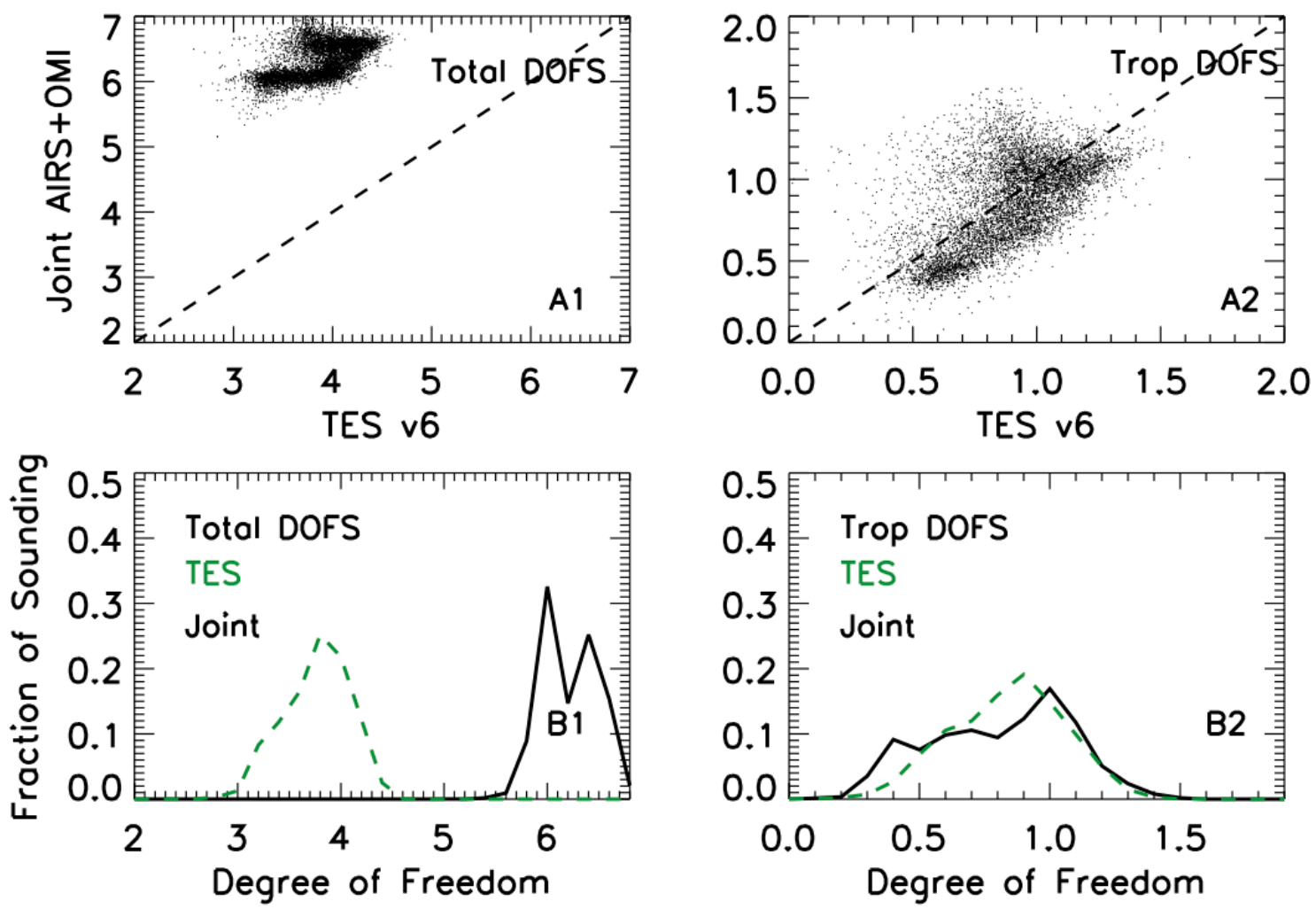

Figure S16: Degree of freedom of signals (DOFS) for May 2006 monthly mean O$_{3}$ over globe shown in Fig. S5. (A1) total DOFS; (A2) tropospheric DOFS; and (B1) histogram of total DOFS: joint AIRS+OMI (black line) and TES version 6 (green dash); (B2) 5 histogram of tropospheric DOFS joint AIRS+OMI (black line) and TES version 6 (green dash). 

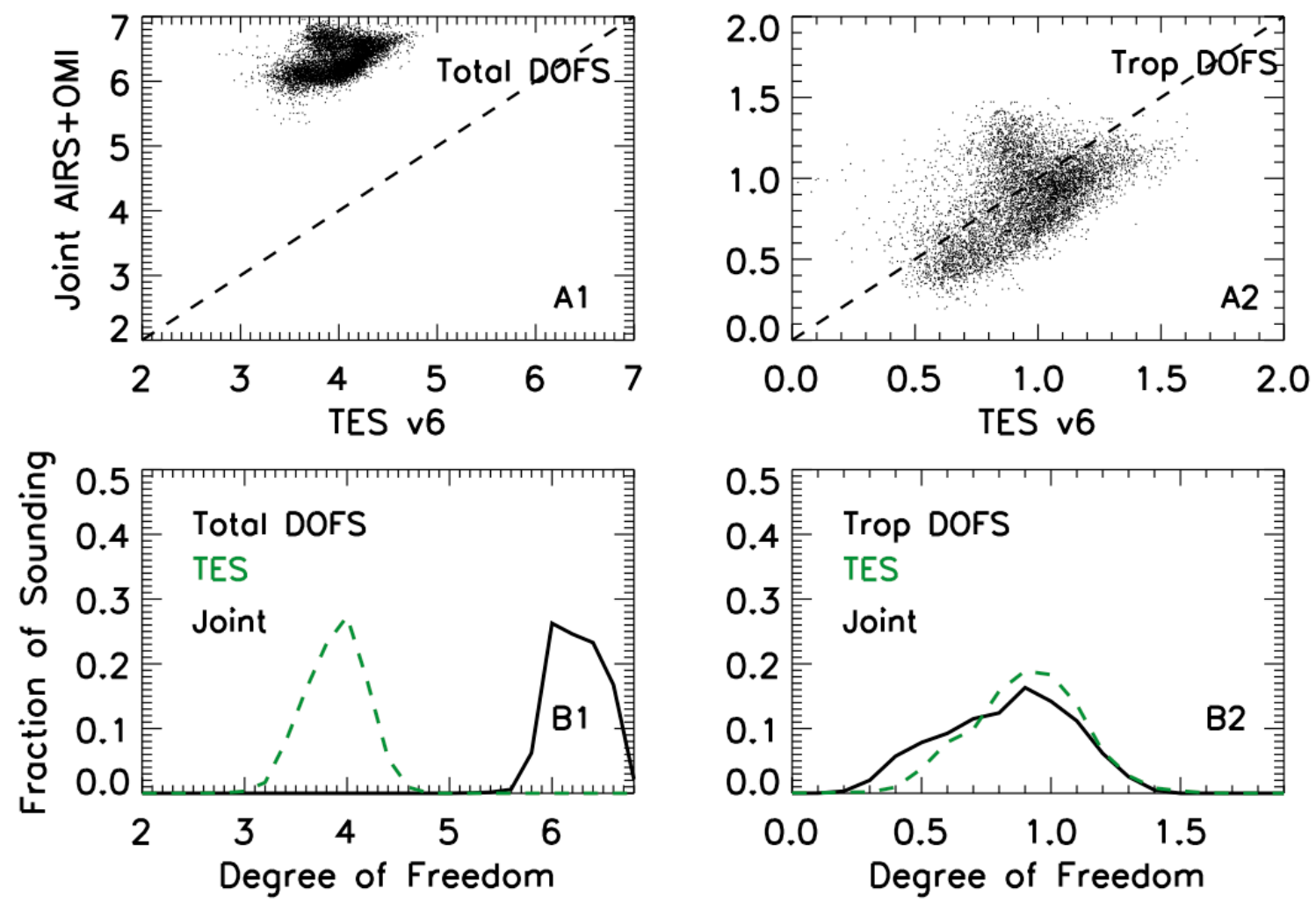

Figure S17: Degree of freedom of signals (DOFS) for June 2006 monthly mean O3 over globe shown in Fig. S6. (A1) total DOFS; (A2) tropospheric DOFS; and (B1) histogram of total DOFS: joint AIRS+OMI (black line) and TES version 6 (green dash); (B2) 5 histogram of tropospheric DOFS joint AIRS+OMI (black line) and TES version 6 (green dash). 

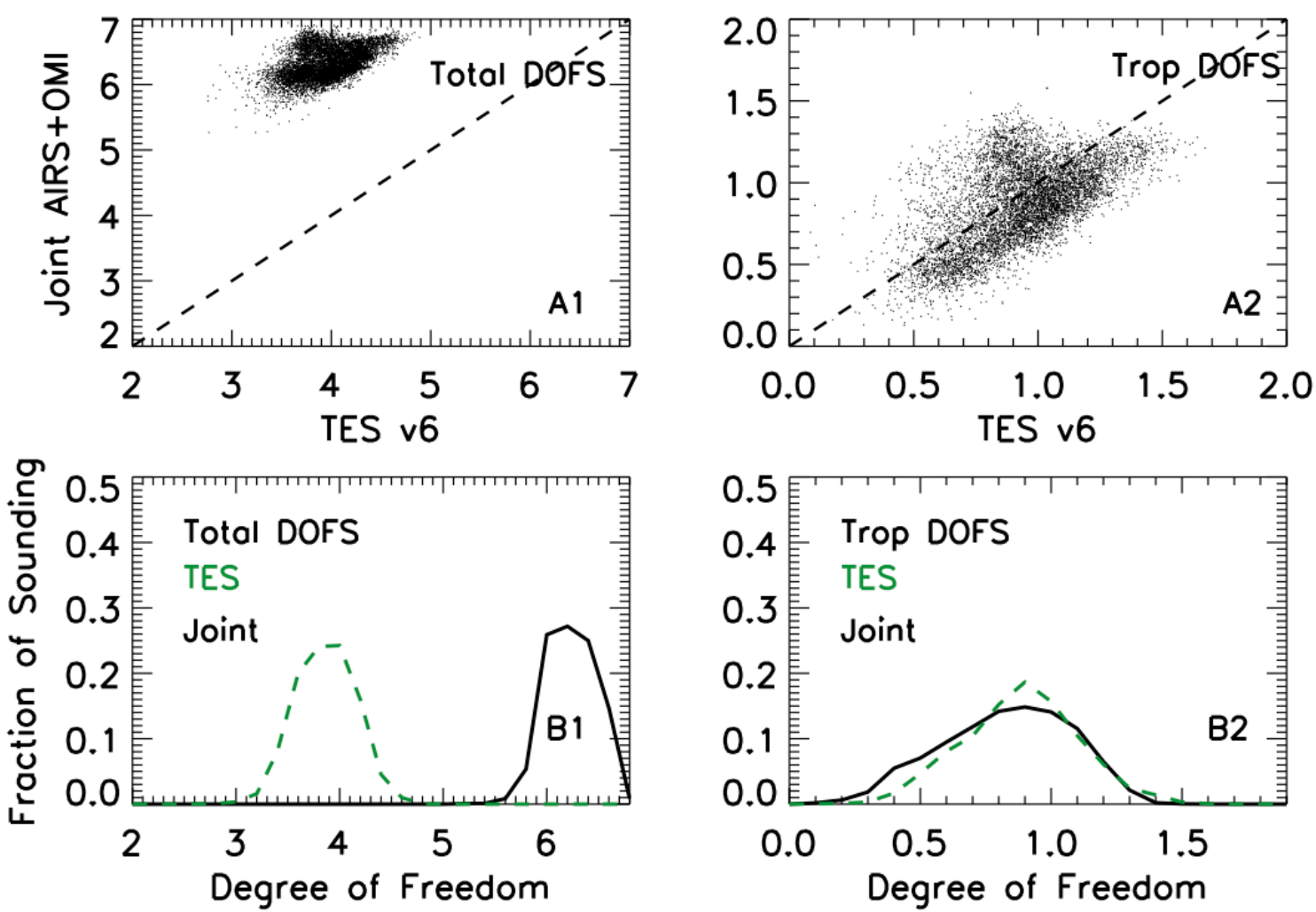

Figure S18: Degree of freedom of signals (DOFS) for July 2006 monthly mean O3 over globe shown in Fig. S7. (A1) total DOFS; (A2) tropospheric DOFS; and (B1) histogram of total DOFS: joint AIRS+OMI (black line) and TES version 6 (green dash); (B2) histogram of tropospheric DOFS joint AIRS+OMI (black line) and TES version 6 (green dash). 

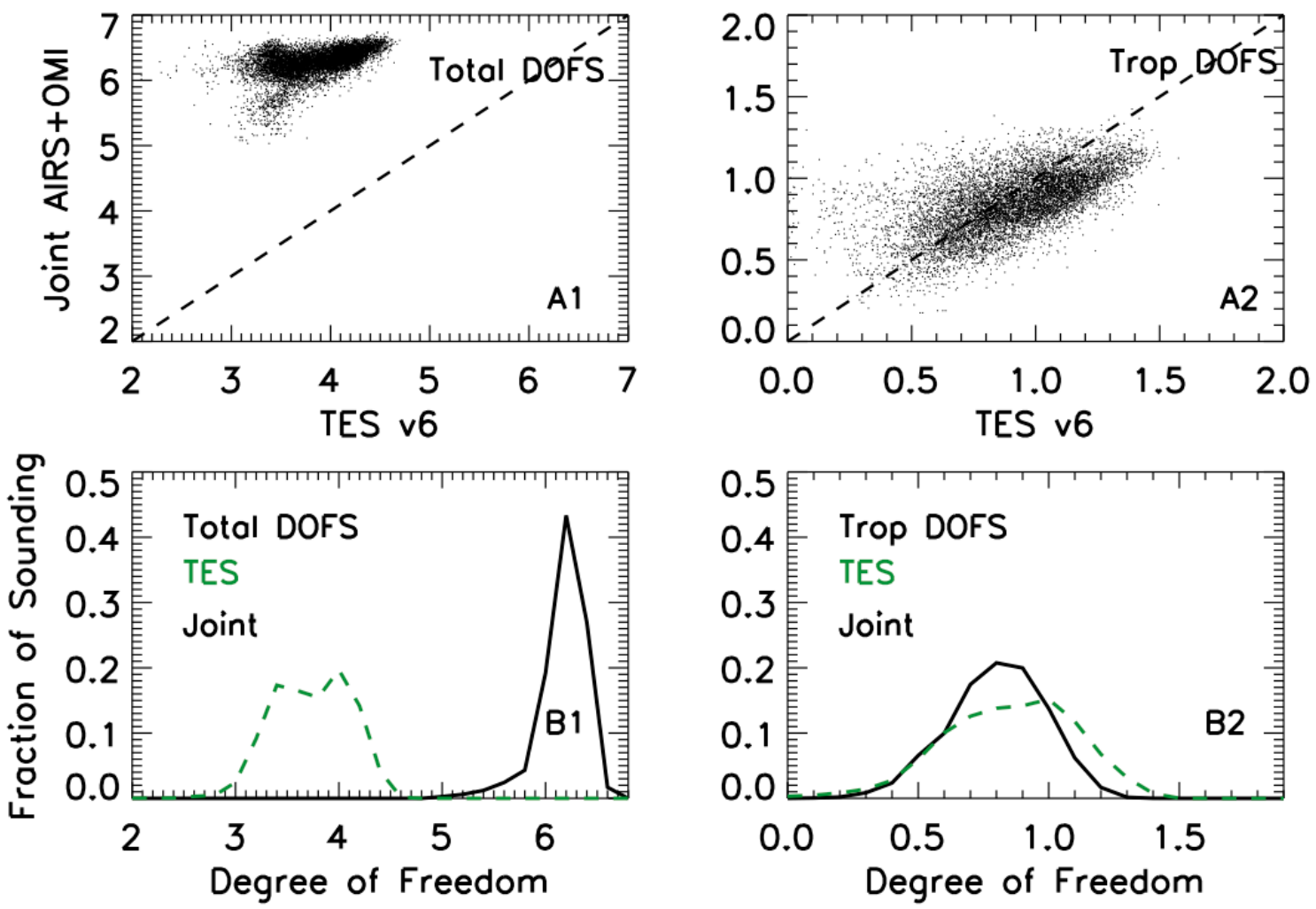

Figure S19: Degree of freedom of signals (DOFS) for September 2006 monthly mean $\mathrm{O}_{3}$ over globe shown in Fig. S8. (A1) total DOFS; (A2) tropospheric DOFS; and (B1) histogram of total DOFS: joint AIRS+OMI (black line) and TES version 6 (green dash); (B2) histogram of tropospheric DOFS joint AIRS+OMI (black line) and TES version 6 (green dash). 

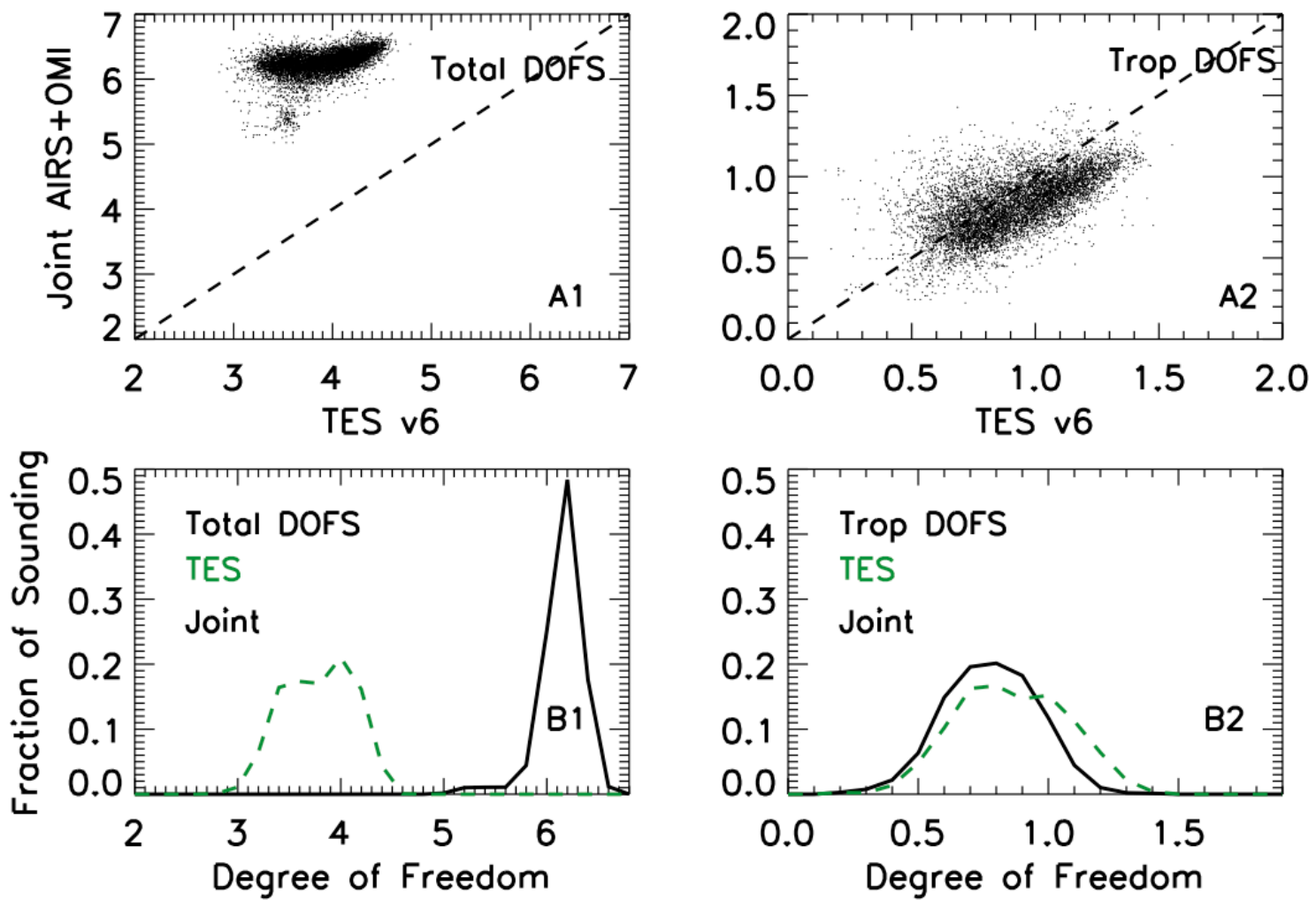

Figure S20: Degree of freedom of signals (DOFS) for October 2006 monthly mean $\mathrm{O}_{3}$ over globe shown in Fig. S9. (A1) total DOFS; (A2) tropospheric DOFS; and (B1) histogram of total DOFS: joint AIRS+OMI (black line) and TES version 6 (green dash); (B2) histogram of tropospheric DOFS joint AIRS+OMI (black line) and TES version 6 (green dash). 

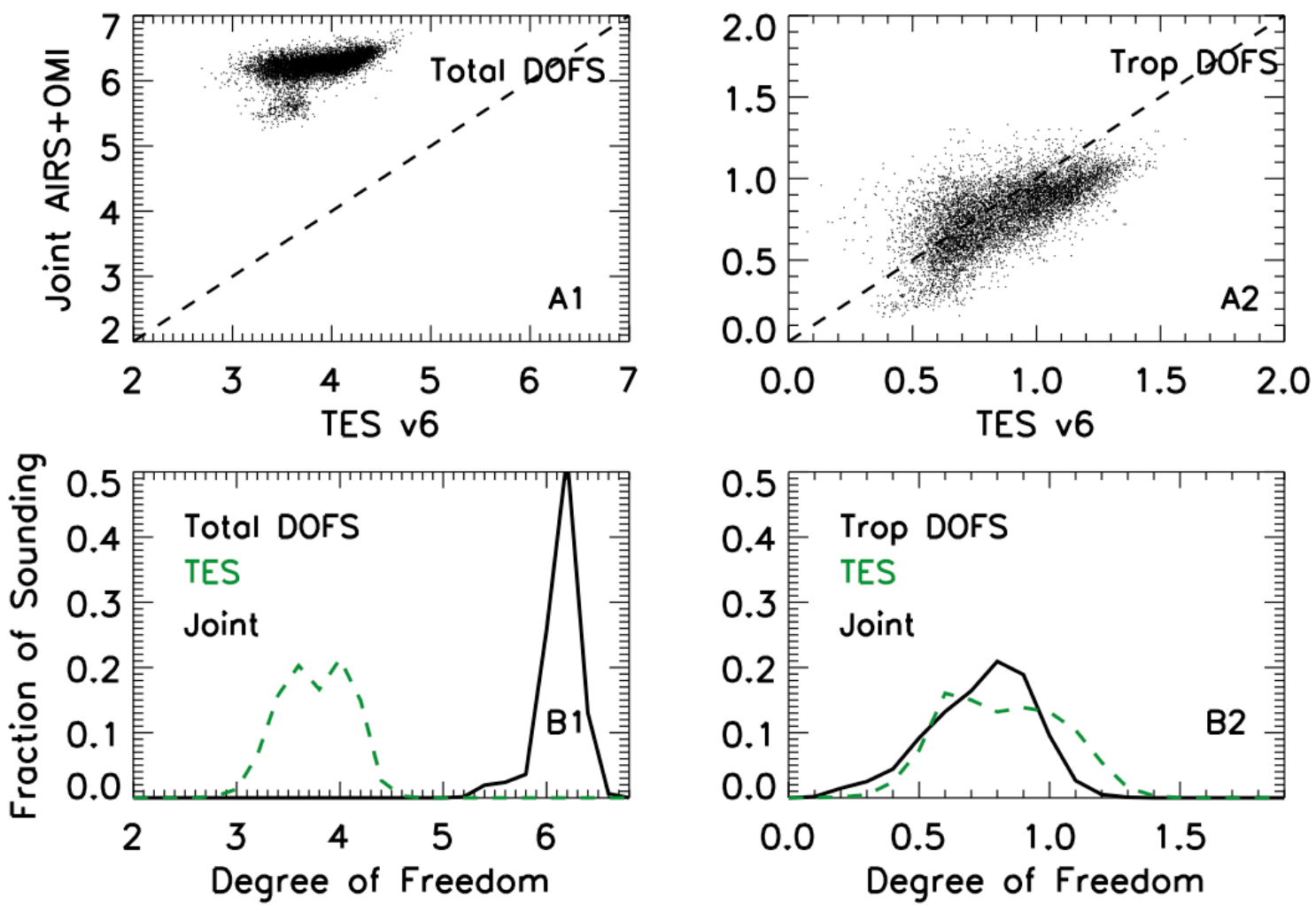

Figure S21: Degree of freedom of signals (DOFS) for November 2006 monthly mean $\mathrm{O}_{3}$ over globe shown in Fig. S10. (A1) total DOFS; (A2) tropospheric DOFS; and (B1) histogram of total DOFS: joint AIRS+OMI (black line) and TES version 6 (green dash); (B2) histogram of tropospheric DOFS joint AIRS+OMI (black line) and TES version 6 (green dash). 

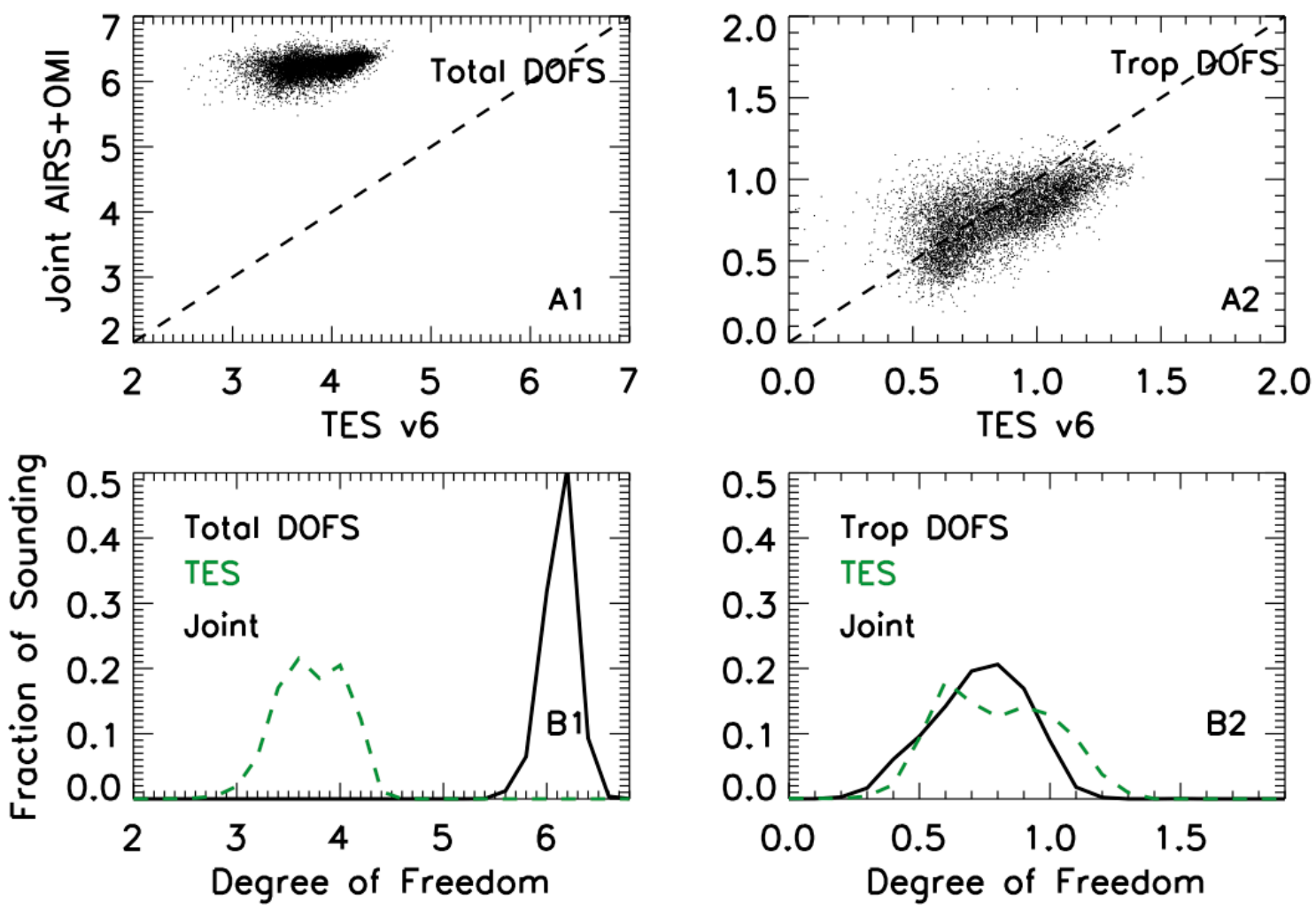

Figure S22: Degree of freedom of signals (DOFS) for December 2006 monthly mean $\mathrm{O}_{3}$ over globe shown in Fig. S11. (A1) total DOFS; (A2) tropospheric DOFS; and (B1) histogram of total DOFS: joint AIRS+OMI (black line) and TES version 6 (green dash); (B2) histogram of tropospheric DOFS joint AIRS+OMI (black line) and TES version 6 (green dash). 

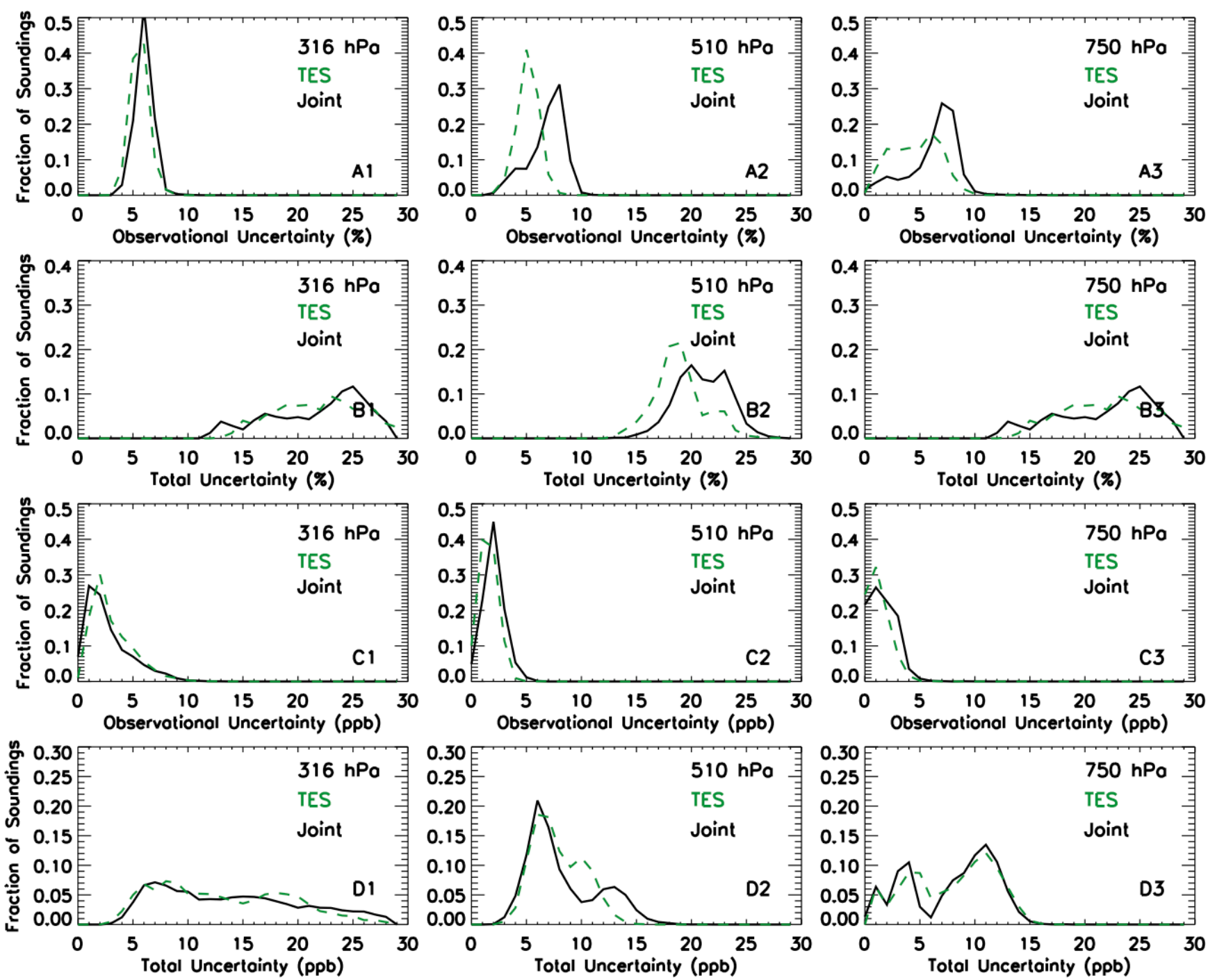

Figure S23: Estimated error of retrieved global $O_{3}$ concentration for January 2006 shown in Fig. S1. (A1-A3) observational error; (B1-B3) total error; (C1-C3) observational error in ppb; (D1-D3) total error in ppb. Joint AIRS+OMI data are shown in black line, and TES version 6 data are shown in green dash. 

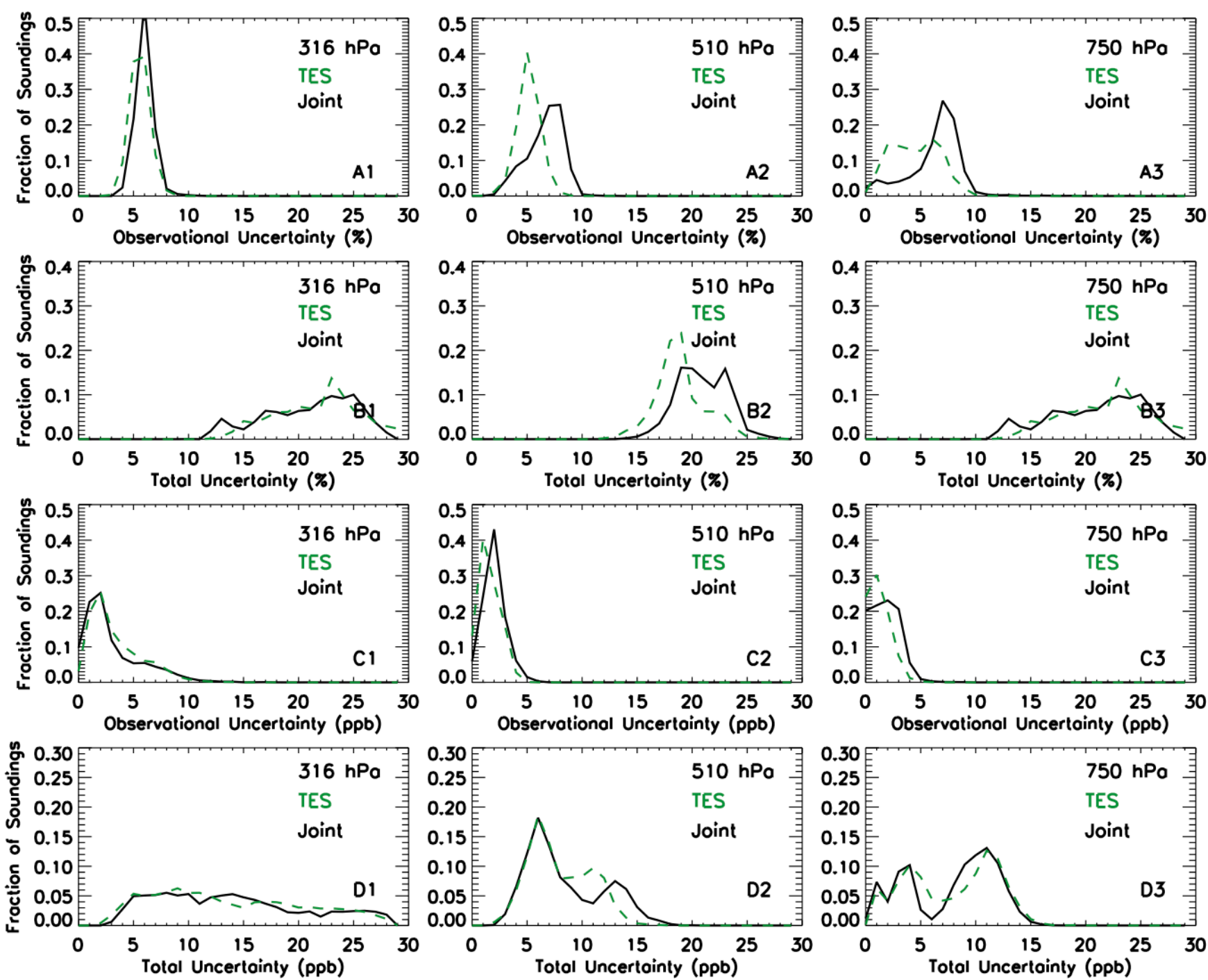

Figure S24: Estimated error of retrieved global $\mathrm{O}_{3}$ concentration for February 2006 shown in Fig. S2. (A1-A3) observational error; (B1-B3) total error; (C1-C3) observational error in ppb; (D1-D3) total error in ppb. Joint AIRS+OMI data are shown in black line, and TES version 6 data are shown in green dash. 

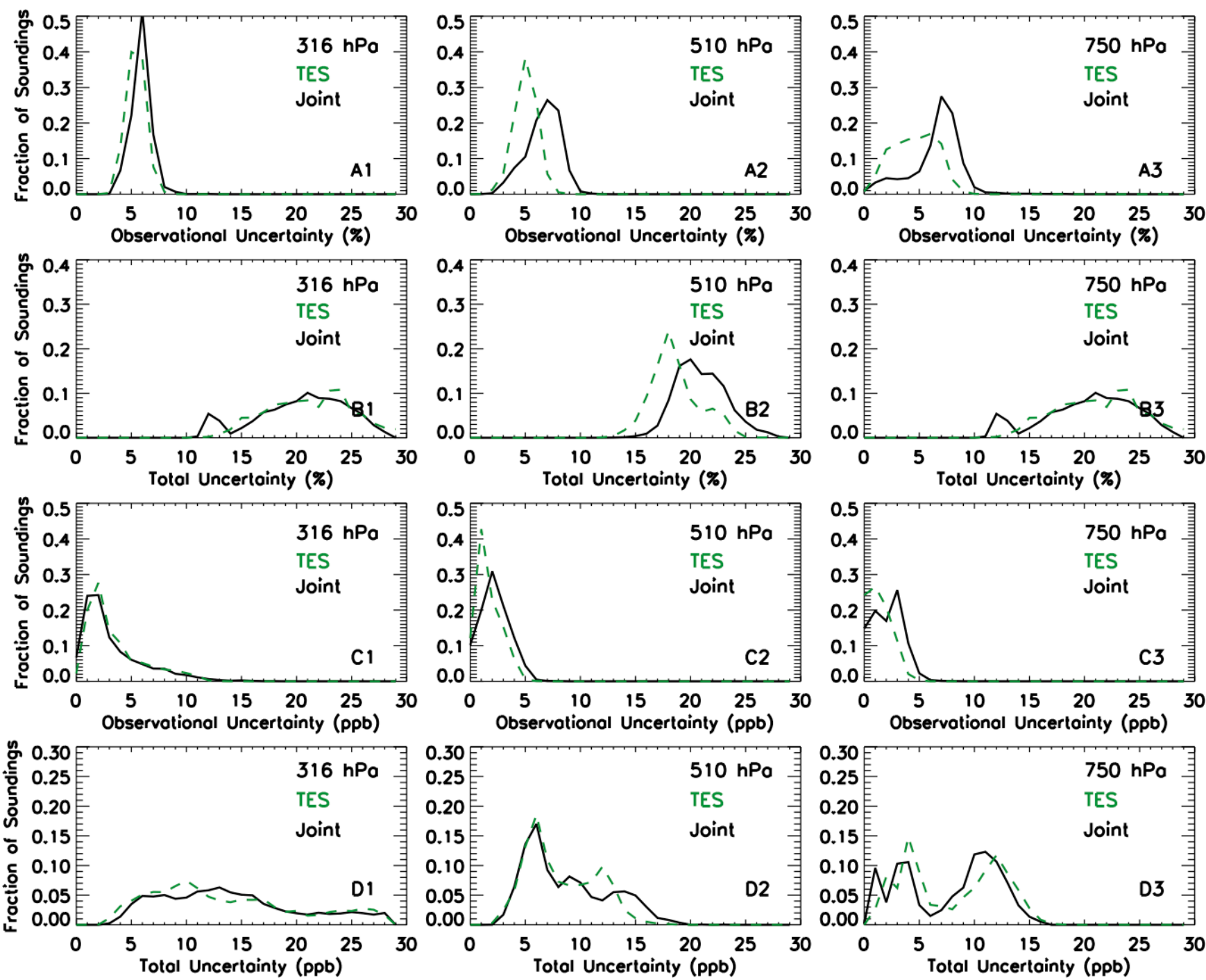

Figure S25: Estimated error of retrieved global $O_{3}$ concentration for March 2006 shown in Fig. S3. (A1-A3) observational error; (B1-B3) total error; (C1-C3) observational error in ppb; (D1-D3) total error in ppb. Joint AIRS+OMI data are shown in black line, and TES version 6 data are shown in green dash. 

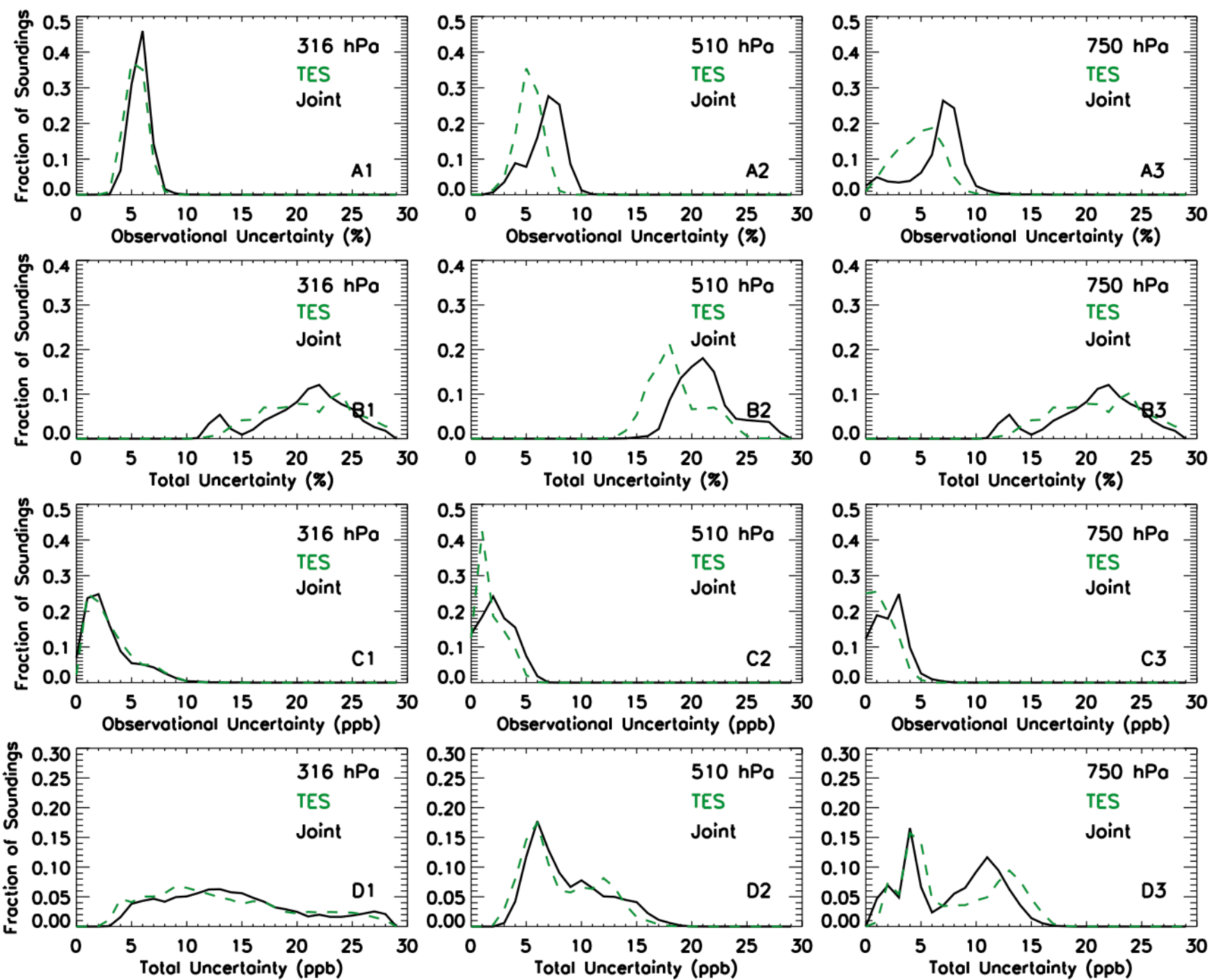

Figure S26: Estimated error of retrieved global $O_{3}$ concentration for April 2006 shown in Fig. S4. (A1-A3) observational error; (B1-B3) total error; (C1-C3) observational error in ppb; (D1-D3) total error in ppb. Joint AIRS+OMI data are shown in black line, and TES version 6 data are shown in green dash. 

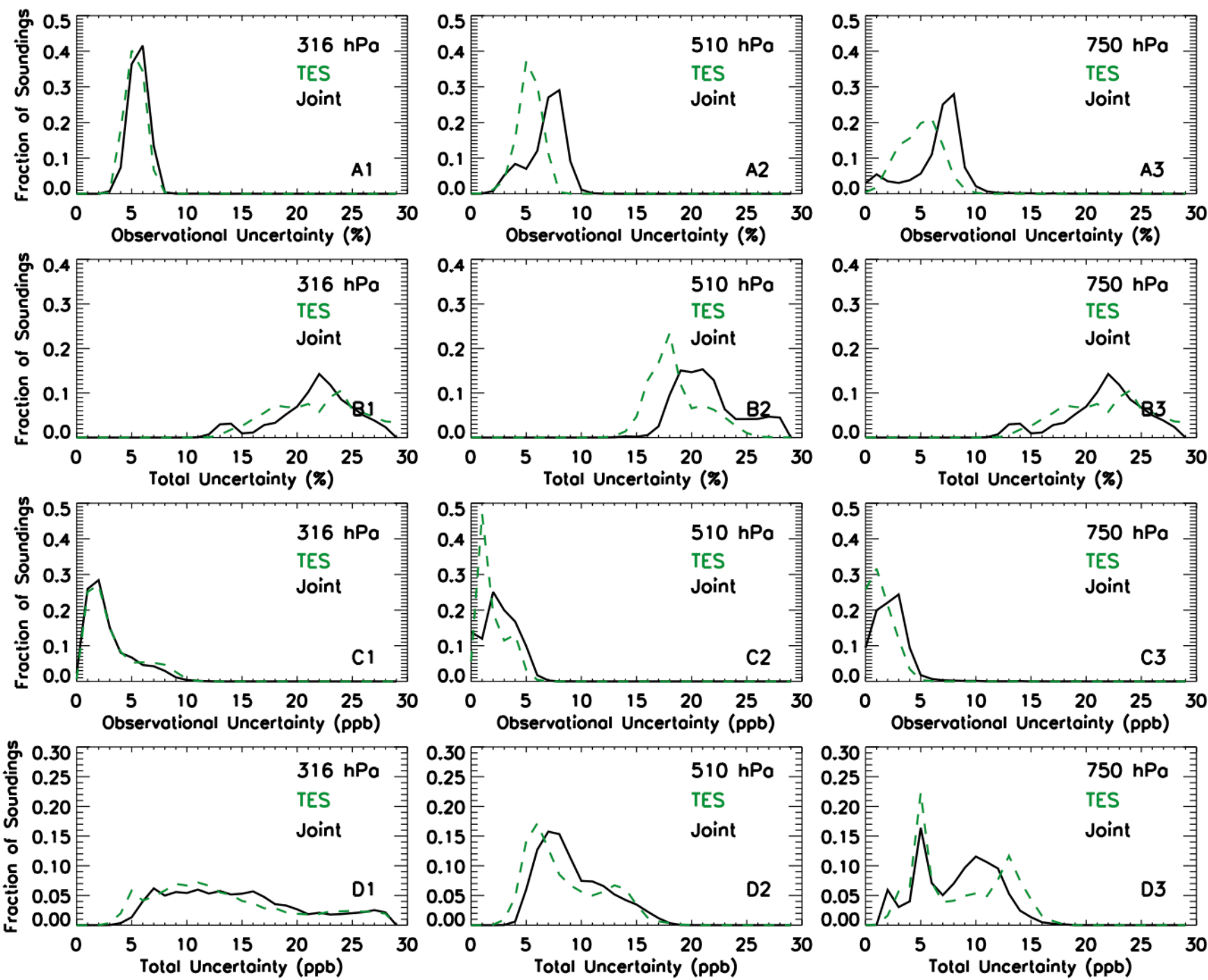

Figure S27: Estimated error of retrieved global $O_{3}$ concentration for May 2006 shown in Fig. S5. (A1-A3) observational error; (B1-B3) total error; (C1-C3) observational error in ppb; (D1-D3) total error in ppb. Joint AIRS+OMI data are shown in black line, and TES version 6 data are shown in green dash. 

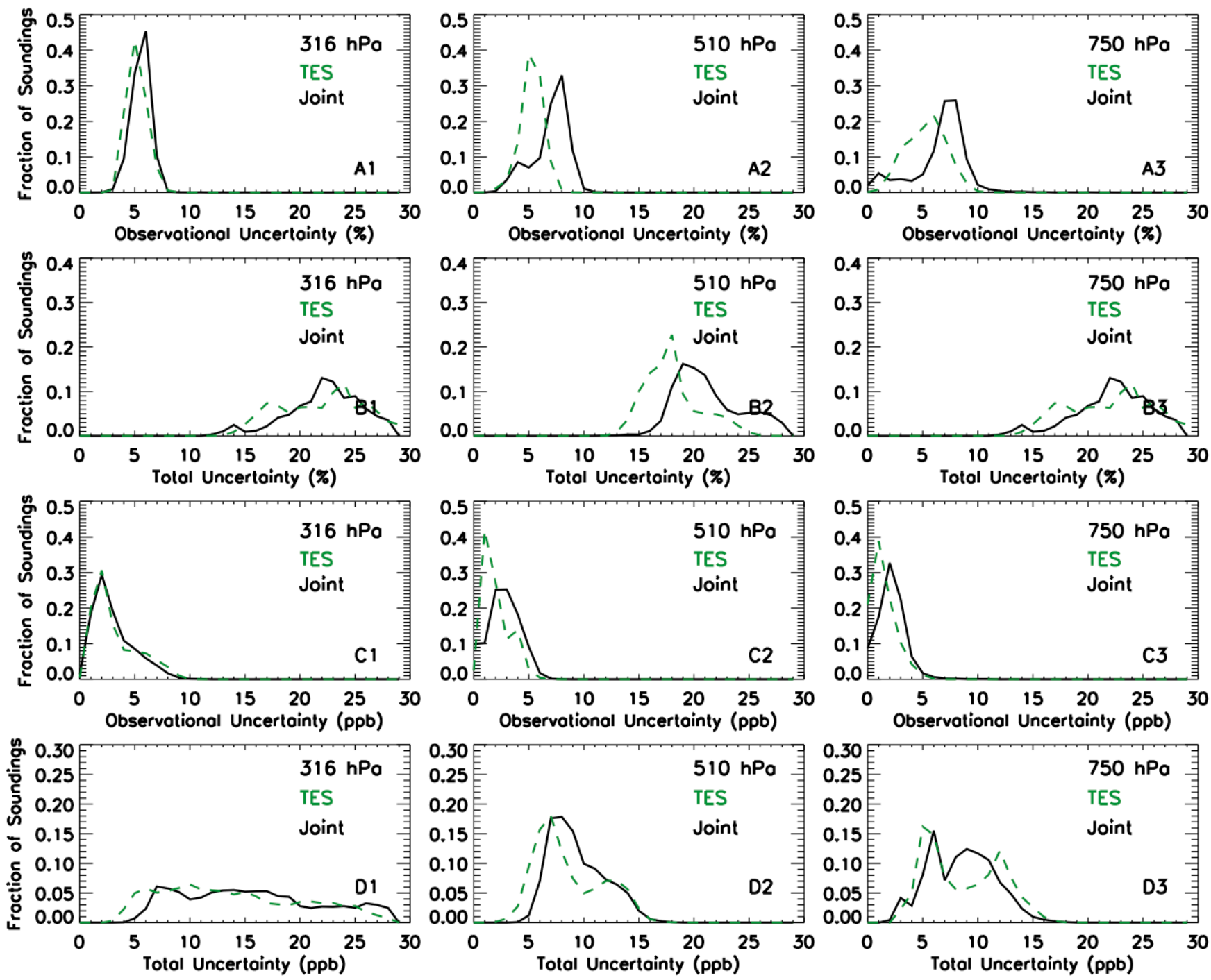

Figure S28: Estimated error of retrieved global $O_{3}$ concentration for June 2006 shown in Fig. S6. (A1-A3) observational error; (B1-B3) total error; (C1-C3) observational error in ppb; (D1-D3) total error in ppb. Joint AIRS+OMI data are shown in black line, and TES version 6 data are shown in green dash. 

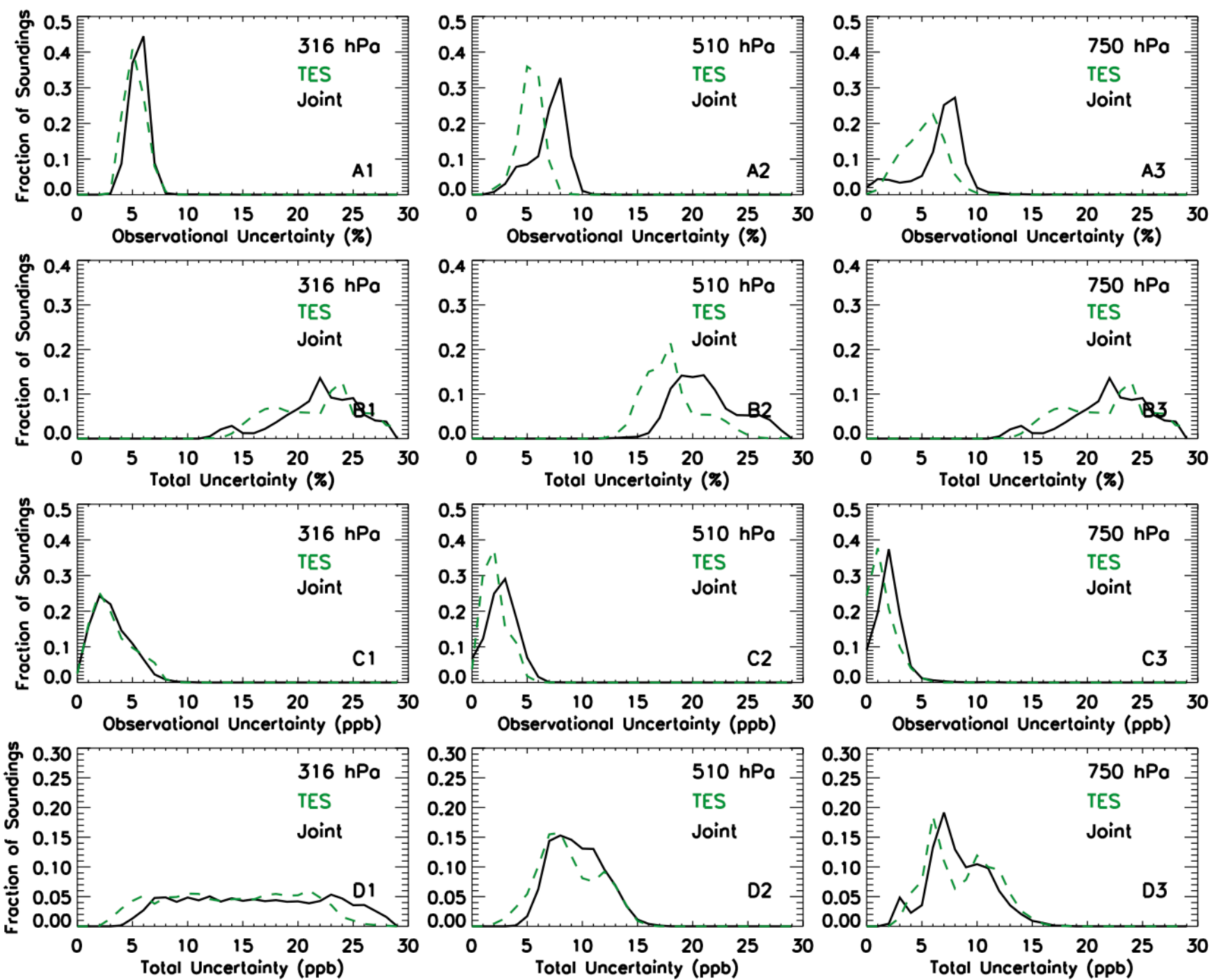

Figure S29: Estimated error of retrieved global $O_{3}$ concentration for July 2006 shown in Fig. S7. (A1-A3) observational error; (B1-B3) total error; (C1-C3) observational error in ppb; (D1-D3) total error in ppb. Joint AIRS+OMI data are shown in black line, and TES version 6 data are shown in green dash. 

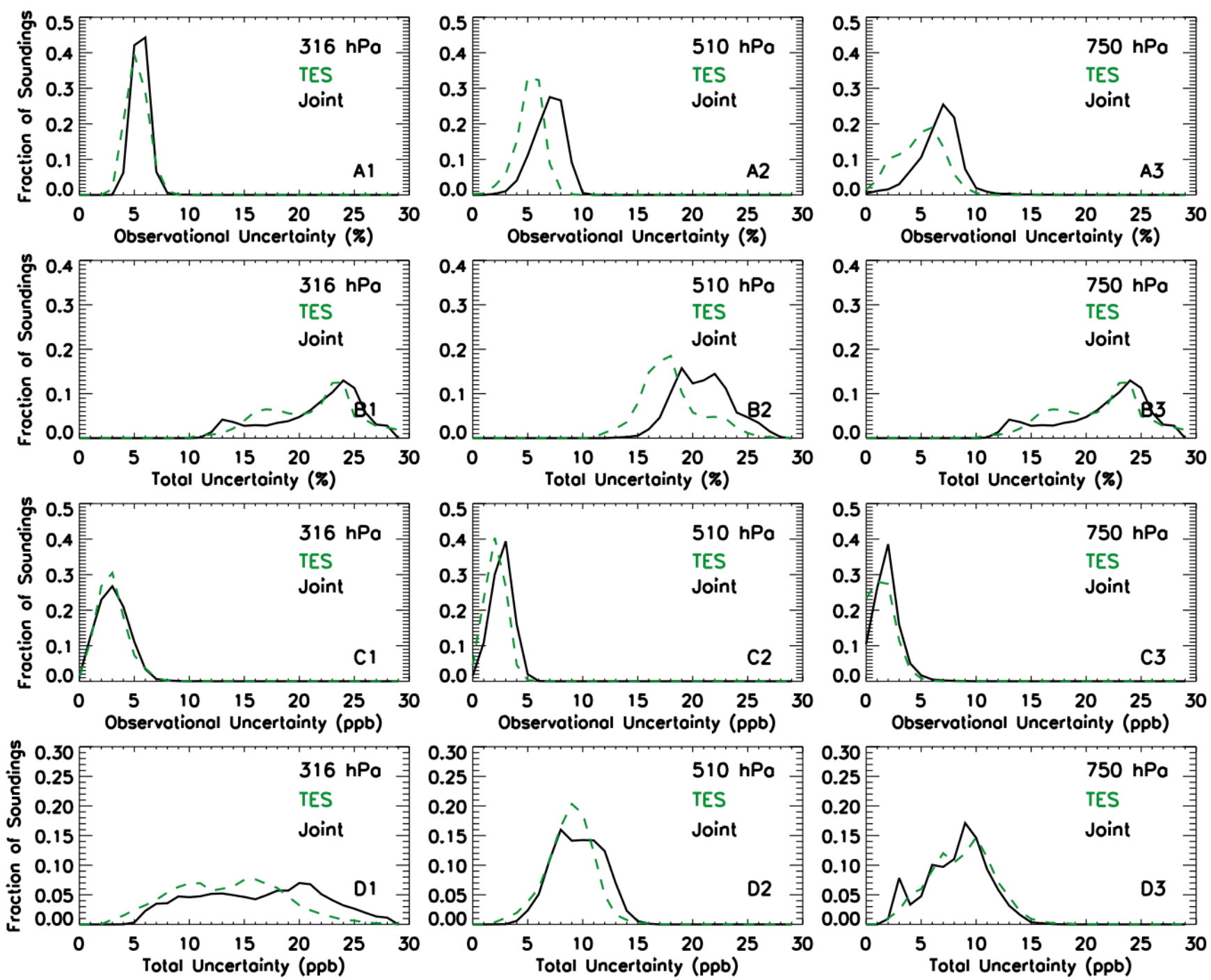

Figure S30: Estimated error of retrieved global $\mathrm{O}_{3}$ concentration for September 2006 shown in Fig. S8. (A1-A3) observational error; (B1-B3) total error; (C1-C3) observational error in ppb; (D1-D3) total error in ppb. Joint AIRS+OMI data are shown in black line, and TES version 6 data are shown in green dash. 

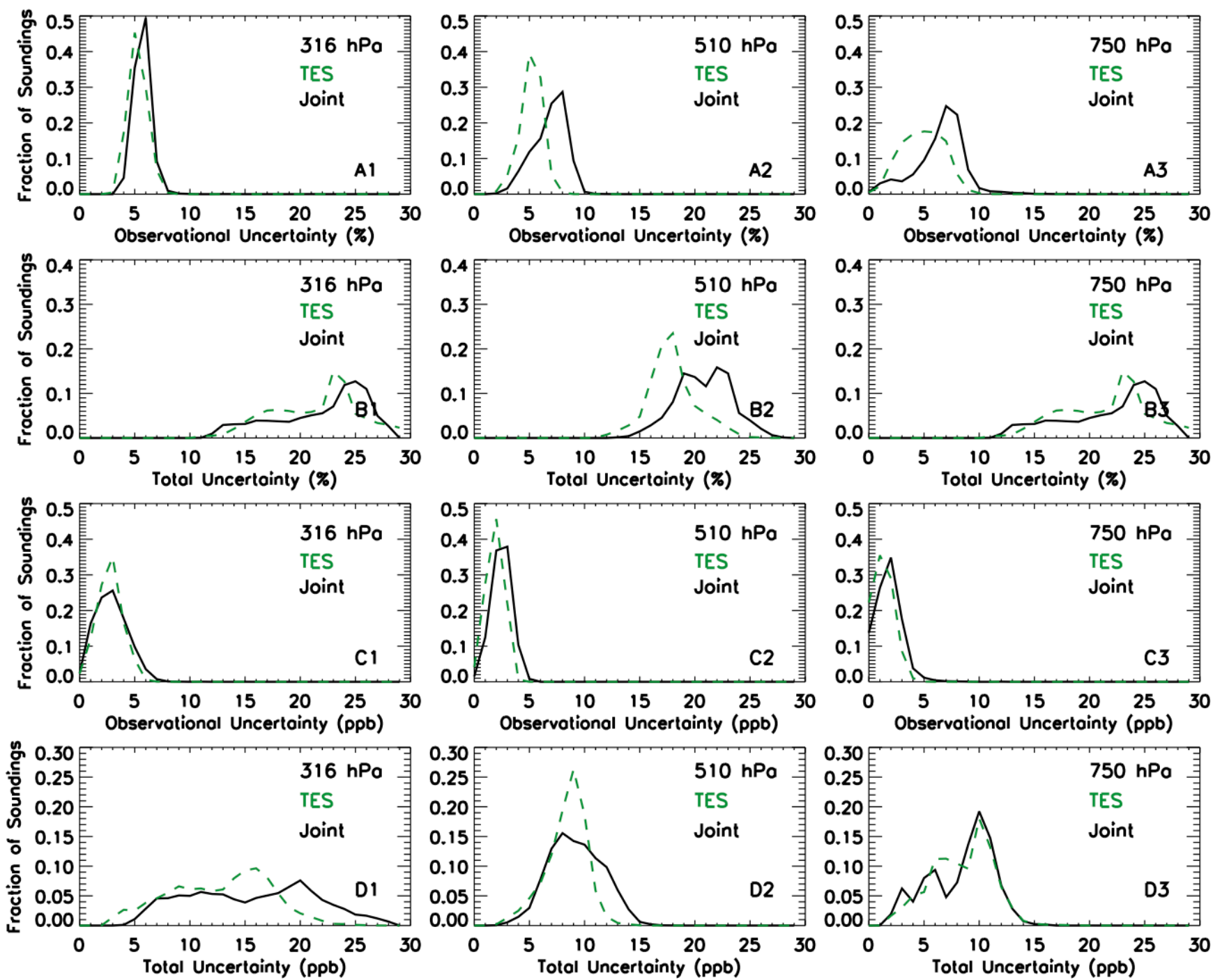

Figure S31: Estimated error of retrieved global $O_{3}$ concentration for October 2006 shown in Fig. S9. (A1-A3) observational error; (B1-B3) total error; (C1-C3) observational error in ppb; (D1-D3) total error in ppb. Joint AIRS+OMI data are shown in black line, and TES version 6 data are shown in green dash. 

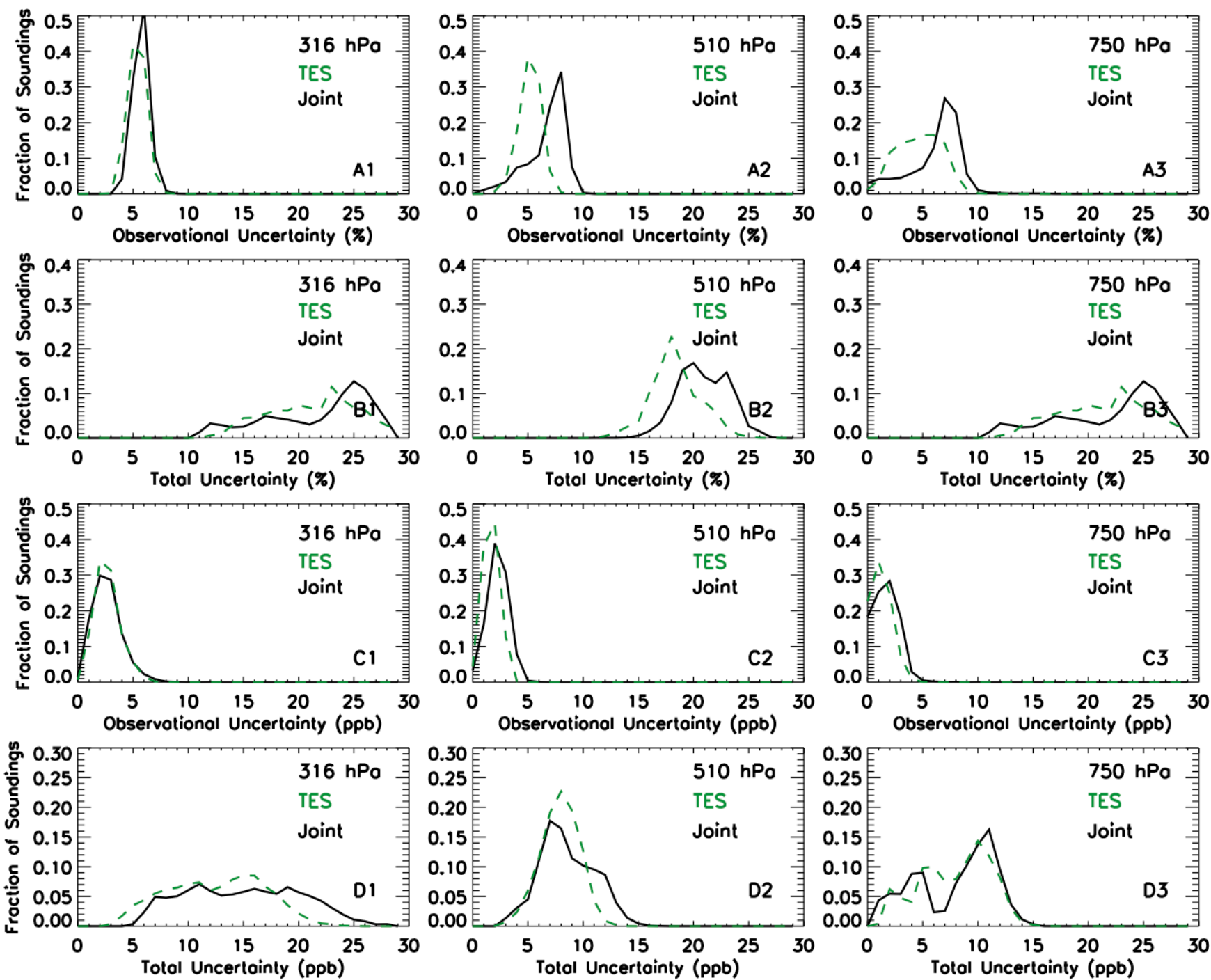

Figure S32: Estimated error of retrieved global $O_{3}$ concentration for November 2006 shown in Fig. S10. (A1-A3) observational error; (B1-B3) total error; (C1-C3) observational error in ppb; (D1-D3) total error in ppb. Joint AIRS+OMI data are shown in black line, and TES version 6 data are shown in green dash. 

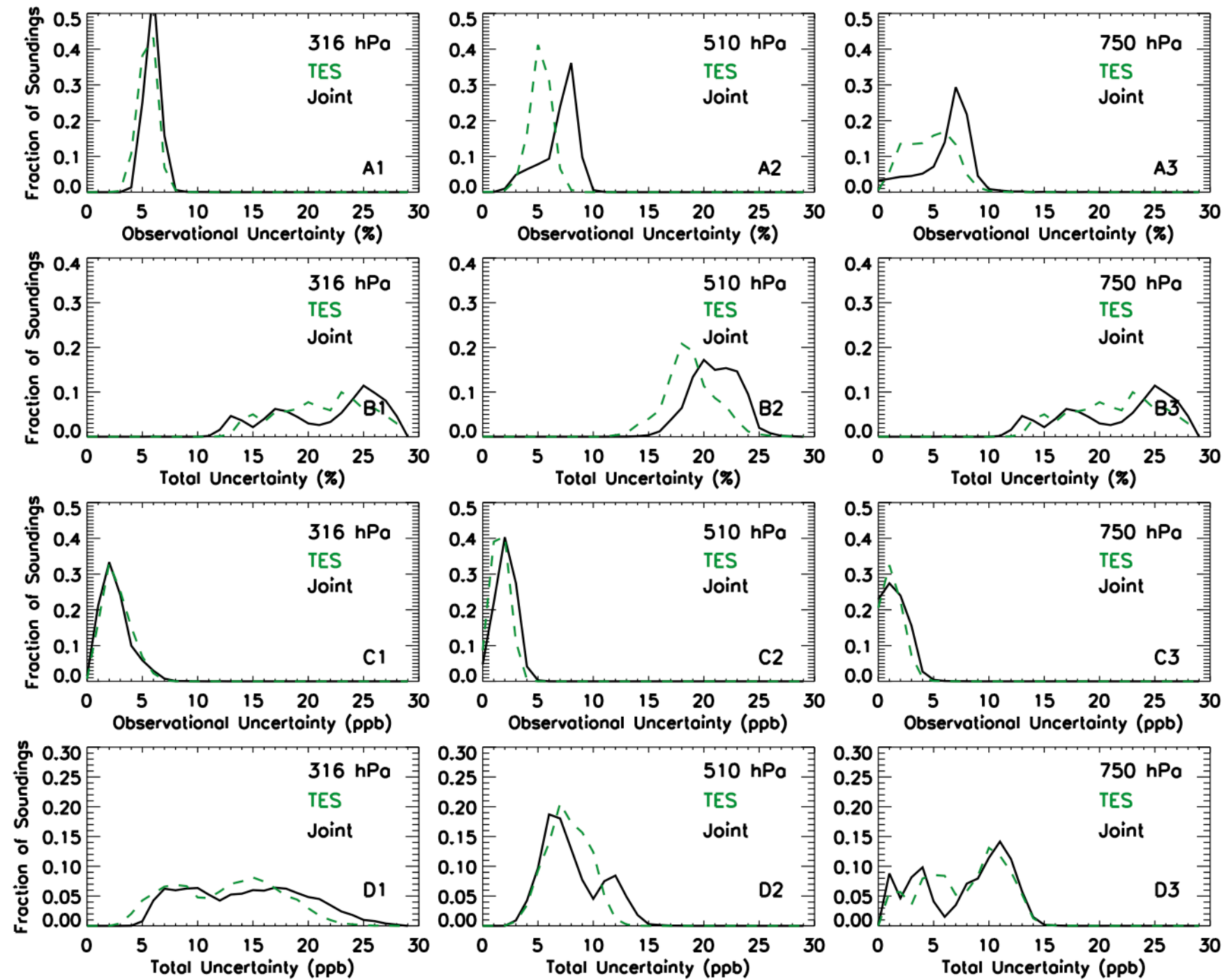

Figure S33: Estimated error of retrieved global $\mathrm{O}_{3}$ concentration for December 2006 shown in Fig. S11. (A1-A3) observational error; (B1-B3) total error; (C1-C3) observational error in ppb; (D1-D3) total error in ppb. Joint AIRS+OMI data are shown in black line, and TES version 6 data are shown in green dash. 